\title{
Dynamic Contract Design of Product-Service Supply Chain considering Consumers' Strategic Behavior and Service Quality
}

\author{
Dafei Wang $\mathbb{D D}^{1}{ }^{1}$ Tinghai Ren, ${ }^{1}$ Xueyan Zhou ${ }^{D},{ }^{2}$ Kaifu Yuan, ${ }^{1}$ and Qingren He ${ }^{3,4}$ \\ ${ }^{1}$ School of Business Administration, Guizhou University of Finance and Economics, Guiyang 550025, China \\ ${ }^{2}$ School of Information, Guizhou University of Finance and Economics, Guiyang 550025, China \\ ${ }^{3}$ School of Management, Guizhou University, Guiyang 550025, China \\ ${ }^{4}$ School of Economics and Management, Beihang University, Beijing 100191, China
}

Correspondence should be addressed to Xueyan Zhou; zhouxueyangufe@163.com

Received 4 May 2021; Revised 24 June 2021; Accepted 29 June 2021; Published 9 July 2021

Academic Editor: Baogui Xin

Copyright (C) 2021 Dafei Wang et al. This is an open access article distributed under the Creative Commons Attribution License, which permits unrestricted use, distribution, and reproduction in any medium, provided the original work is properly cited.

With increasing market competition and rapid development of service economy, more and more enterprises are shifting from providing products or services to providing product-service systems (PSSs) that integrate products and services, in order to improve competitiveness and profitability. Meanwhile, consumers have strategic delayed purchasing behavior when purchasing the PSS and high requirements for service quality. This paper investigates the two-period pricing and service quality decisions of product-service supply chain (PSSC) considering consumers' strategic behavior under decentralized and centralized scenarios. The equilibrium results are compared in two scenarios. In order to eliminate performance loss under the decentralized scenario, we design two-period dynamic contracts to coordinate the PSSC. Furthermore, numerical simulation is provided to verify the feasibility of the contracts. The following conclusions can be drawn: (1) the higher the service input-efficiency, the more beneficial for alleviating consumers' strategic purchase behavior under two scenarios, but this mitigation effect is more obvious under the centralized scenario. (2) Compared with the centralized scenario, the service quality is lower, the two-period PSS sales prices are higher, and the two-period profit is lower under the decentralized scenario. The proportion of service valuation (accounts for the valuation of PSS) will promote the widening of the service quality gap under two scenarios, but in some cases, the service inputefficiency will weaken the promotion effect of the proportion of service valuation. (3) The design of the two-period combined contracts depends on the proportion of service valuation. When the proportion of service valuation is high, the "two-period revenue sharing + service-cost sharing" combined dynamic contract can achieve PSSC perfect coordination. However, when the proportion of service valuation is low, it is necessary to design complexity combined dynamic contract which can achieve PSSC perfect coordination.

\section{Introduction}

In the face of fierce market competition and the product lifecycle which is constantly shortened, dynamic price reduction strategy has become an effective way for firms to respond to competition and increase sales. For example, in China, during the 618 (June 18th) and Singles' Day (November 11th) each year, many firms adopt price-cutting promotion strategies to attract more consumers to buy, such as the distribution of red envelopes and coupons. During the
618 period in 2019, Jingdong's total revenue was 201.5 billion CNY, up by $26.57 \%$ year on year [1]. Tmall's income on Singles' Day was 268.4 billion CNY in 2019, growing by $25.71 \%$, and logistics orders are 1.292 billion orders, an increase of $24 \%$ [2]. Because firms often cut prices for promotion, consumers become more and more rational when buying. Consumers are aware that firms may cut prices, and consumers will strategically choose the time to purchase to maximize their own utility. This type of consumer is called strategic consumer, and the corresponding 
strategic purchase behavior is called consumers' strategic behavior. If a firm ignores consumers' strategic behavior in pricing decisions, it will cause huge losses to the firm's profit $[3,4]$. Therefore, firms pay more and more attention to consumers' strategic behavior in the pricing process.

In a product-service supply chain (PSSC) that provides both product and service, consumers' strategic behavior still exists. In this paper, the PSSC is composed of a manufacturer and a service provider, the manufacturer provides a product to the service provider, and the service provider integrates the product and the service into a product-service system (PSS) and provides the PSS to consumers. Obviously, the impact of consumers' strategic behavior on the PSSC is more complex, which will not only affect the product demand of the manufacturer in different sales periods but also delay in purchasing and using the product due to consumers waiting for price reduction. The consumers' strategic behavior will affect the service demands of the service provider at different sales periods and ultimately affect the product revenue and service revenue of the entire PSSC. This situation is common in the mobile communication industry, such as the mobile phone manufacturer provides the mobile phone to the communication operator, and the communication operator packs the mobile phone and the communication service and sells it to consumers. Due to the high frequency of mobile phone price changes, for example, the price of the iPhone 11 Pro Max just launched in September 2019 was up to 10,000 CNY, and the price was reduced by $1,300 \mathrm{CNY}$ after a month [5]. As of August 2020, the price of this phone had been reduced by 2,500 CNY [6]. Consumers are more inclined to buy after lowering prices, which will not only affect the current mobile phone sales, but also reduce the use time of communication services due to delayed use of mobile phones, which will adversely affect the service revenue of communication operators. On the other hand, with the rapid development of the service economy, consumers have higher requirements for service quality. The firm improves consumer satisfaction by improving service quality, which in turn promotes service demand. In reality, consumers often complain about service problems such as slow network speeds and unstable communication signals of the communication operator, so the communication operator has adopted a variety of measures to improve service quality, such as technology upgrades from the original $4 \mathrm{G}$ to $5 \mathrm{G}$, and the addition of base stations and network optimization. However, the improvement of service quality is bound to increase the service cost of the service provider. Therefore, in the face of consumers' increasing requirements for service quality and strategic purchase behavior, how should supply chain members set prices, and how to design effective dynamic contracts to coordinate supply chain members' pricing decisions behavior to achieve the best supply chain performance, that is a problem worthy of investigating. The research of this paper is mainly to solve the following problems:

(1) How should supply chain members make decisions under decentralized and centralized scenarios? What are the relationships between the equilibrium results under the two scenarios?
(2) How does the service element in the PSS affect the consumers' strategic behavior and the deviation of the two-period equilibrium results under the two scenarios?

(3) Facing the consumers' strategic behavior in the PSS under the condition of improving service quality, how to design effective contracts to achieve the perfect coordination of the PSSC?

In order to solve the above problems, we consider a PSSC, which consists of a manufacturer and a service provider. The manufacturer sells products, and the service provider integrates the product and service into PSS to sell to consumers. We also consider the impact of service quality on consumers' purchasing behavior. In order to analyze the performance loss of the PSSC under the decentralized scenario, we construct two dynamic decision models in the centralized and the decentralized scenarios. Comparing the equilibrium results in both scenarios, which finds that the two-period sales prices of the PSS are higher, the quality of service and the supply chain profit are lower under the decentralized scenario, which mean that there are decision bias and performance loss of supply chain. Moreover, with the increase of the proportion of service valuation, the degree of distortion of the PSS price is exacerbated, and the gap of service qualities is more obvious under two scenarios. The service provider improves service input-efficiency will inhibit the promotion effect of the proportion of service valuation to price distortion in the first period. In order to eliminate supply chain performance loss, we design twoperiod dynamic contracts related to the proportion of service valuation to adjust decision behavior of supply chain members and achieve optimal improvement of supply chain performance.

The remainder of this paper is arranged as follows. Section 2 reviews the related literature. Section 3 contains the problem description and model assumptions. Centralized and decentralized PSSC decision models are discussed in Sections 4 and 5, respectively. The comparative analysis of the two PSSC decision models is given in Section 6. Section 7 designs two combined dynamic contracts to coordinate the PSSC. Numerical simulations and conclusions are given in Sections 8 and 9 , respectively. We postpone all of the proofs to Appendix.

\section{Literature Review}

The impact of consumers' strategic behavior on the firm decision attracts more scholars' attention, and scholars conduct in-depth research on this topic. Some scholars study the impact of consumers' strategic behavior on the firm dynamic pricing under monopoly and competitive environment $[7,8]$. Besanko and Winston investigate the dynamic pricing problem of a monopoly seller based on multiple sales periods and find that monopolist should adopt price skimming strategy when facing strategic consumers [7]. Based on the literature [7], Liu and Zhang expand a single firm to two firms, investigating the multiperiod price competition of two firms with different product quality, 
finding that consumers' strategic behavior has larger adverse impact on the firm that provides low-quality products [8]. In response to product upgrading, some scholars discuss the impact of consumers' strategic behavior on the product rollover strategies and the firm pricing [9-12]. For example, Liang et al. consider a firm selling products to strategic consumers under two strategies of single rollover and dual rollover, studying the optimal pricing and inventory level of the firm, finding that when the proportion of strategic consumers is high and the degree of new product innovation is low, the firm should adopt single rollover strategy [9]. Liang et al. further study the impact of consumers' strategic behavior on product innovation level and find that consumers' strategic behavior will harm the profit of the firm, but it will increase the product innovation level [10]. Guo and Chen consider the challenges of new product releases to the proliferation of multiple generations of continuous product, studying the impact of consumers' strategic behavior on the two-generation product diffusion strategy. They find that the impact of consumers' strategic behavior on sales and profits largely depends on the price discount rate of the first-generation product under the second-generation product performance improvement [11]. Liu et al. discuss the impact of consumers' strategic behavior on the firm pricing strategies under the conditions of the introduction of a new generation of products and trade-in and find that when the residual value of the old-generation products is high enough, the firm is willing to sell the oldgeneration products to the second period new consumers [12].

In addition, some scholars study pricing issues that consider consumers' strategic behavior under quick response [13-16]. For example, Cachon and Swinney investigate the pricing and ordering decisions of the firm under the quick response and find that the quick response can alleviate the adverse effects of consumers' strategic behavior, achieve the matching of supply and demand, and increase the firm revenue [13]. Cachon and Swinney further study the fast fashion system that combines quick response and enhanced product design and find that both enhanced design and quick response can alleviate consumers' strategic behavior [14]. Wang et al consider that strategic consumers have risk preferences, discussing the impact of quick response on retailers' pricing and ordering decisions, finding that retailers' optimal pricing gradually decreases with strategic consumers' risk preferences, while optimal inventory has nothing to do with it [15]. Dong and Wu study the impact of consumers' strategic behavior on pricing and inventory decisions under the quick response and find that there is a unique equilibrium solution if and only if the degree of consumers' strategic behavior is sufficiently high [16]. Furthermore, Yu et al. consider the uncertainty of new experience product quality information and consumers' strategic behavior, studying the influence of consumer reviews on the dynamic pricing strategy, finding that the firm can control consumer reviews by adjusting the initial price of product, and the more consumer reviews which are possible will have a negative impact on consumer surplus [17]. Du and Chen take into account the uncertainty of the number of strategic consumers and the uncertainty of product evaluation in the market, studying the pricing strategy of new product, finding that the applicable conditions of the two pricing strategies of skimming pricing and penetration pricing [18]. Some scholars separately study the impact of consumers' strategic behavior on pricing in different situations such as product demand learning [19], quality information disclosure [20], cost reduction [21], reference price effects [22, 23], e-commerce platforms [24], and two alternative products (low-carbon products and ordinary products) [25].

Furthermore, some scholars study the impact of consumers' strategic behavior on the decision and contract coordination of supply chain members from the supply chain structure. Su and Zhang discuss the impact of consumers' strategic behavior on the decisions of supply chain members and supply chain performance and find that consumers' strategic behavior will reduce the amount of orders for retailers, and retailers can increase revenue through price commitments [26]. Yang et al. consider different supply chain structures and consumers' strategic behavior, studying the impact of quick response on supply chain decisions [27]. Ahmadi et al. discuss the impact of the gray market and consumers' strategic behavior on supply chain performance under wholesale price contract and quantity discount contract [28]. Lin et al. investigate the pricing and ordering decisions of supply chain members and find that consumers' strategic behavior is beneficial to the manufacturer, and in some cases, it is also beneficial to the retailer and the entire supply chain [29]. Kabul and Parlaktürk discuss the supply chain performance under price commitment or quantity commitment, finding that the commitment is not only detrimental to itself but also detrimental to other members of the supply chain, and the commitment can benefit by designing two-part tariff contract or quantity discount contract [30].

The above literature studies consider the impact of consumers' strategic behavior on product pricing decisions from an enterprise perspective or supply chain perspective and do not consider the impact of service. This paper will extend to the PSSC, construct multiperiod dynamic decision models including consumers' strategic behavior and service, analyzing and comparing dynamic equilibrium results and supply chain profits in two different scenarios, and design dynamic contracts to eliminate performance loss of the decentralized supply chain.

Another type of literature related to this paper is research on PSS and PSSC, which mainly includes qualitative analysis and quantitative analysis. Qualitative research mainly involves basic concepts, classification, design, operation models and methods, application value, etc. [31-36], which provides favorable theoretical support for the research of mathematical models. Quantitative research mainly involves product pricing and service decision [37-41] and contracts design [42-45]. Regarding pricing and service decision, Ferrer et al. consider the mixed bundling of products and multiple services, studying the optimal pricing decisions, applying dynamic programming to obtain the optimal pricing strategy, considering that some firms may not be 
suitable for adopting dynamic pricing, giving two suboptimal fixed prices and comparing with the optimal pricing [37]. Pang and Etzion focus on the firm selling products and complementary online services, among which online services have positive network effects, analyzing bundled pricing and individual pricing, finding that although bundled pricing can increase consumer surplus and social welfare, the monopolist do not use bundling sales, and network effects will lead to insufficient service supply [38]. Yang and $\mathrm{Ng}$ investigate the problem of bundling sales of products and services in the communications industry, using nonlinear integer programming to obtain the optimal pricing strategy, comparing the three strategies of individual sales, mixed bundling, and pure bundling, giving the condition that the mixed bundling strategy is the optimal strategy [39]. Zhang et al. consider a manufacturer to provide product and value-added service and discuss the pricing of value-added service and product under information asymmetry about value-added service quality [40]. Dan et al. further consider a manufacturer and a retailer to provide product and value-added services in double-channel PSSC, research warranty service, and value-added service decisions [41].

Moreover, some scholars investigate the effect of contract design on improving the performance of supply chain members from the perspective of PSSC. Xie et al. consider that the retailer has private value-added service-cost information, studying optimal pricing and service level decision, discussing three types of contracts, finding that retail price maintenance contract is more beneficial to the manufacturer and consumers, and franchise fee contract is more beneficial to the retailer [42]. Yang and Xiao study product pricing and service quality decision based on consumers' loss-averse and reference effect on service quality and design a combination contract of quantity discount and service subsidy to coordinate the PSSC [43]. Chen et al. consider a two-level PSSC composed of a manufacturer and a retailer facing random demand and discuss the product pricing and after-sales service level under a wholesale price contract or a revenue sharing contract when the manufacturer or retailer provides after-sales service [44]. Pascual et al. propose a quantitative method of contract design for use-oriented PSS and demonstrate the performance of applying this method through a case [45]. Furthermore, some scholars have studied capacity allocation problem of PSS. Wang et al. consider production service systems consisting of a service center and a manufacturing facility, which provides products and related services, and study the capacity allocation problem of the production service systems [46]. Moreover, $\mathrm{Xu}$ et al. review 71 research literature studies of the PSSC and analyze the future research opportunities and research strategies of the PSSC [47]. In addition, there is also research related to the paper involving contract design in the supply chain. Taleizadeh et al. consider product demand affected by sales price, greenness, and refund price and study supply chain decisions under cost sharing contract [48].

The literature just listed mainly studies pricing and contract design of product and service from the perspective of the firm or supply chain, without considering consumers' strategic behavior. In reality, due to the rapid development of information technology and the Internet, it has become increasingly convenient for consumers to obtain information about products and services, leading consumers to become more and more rational in the purchase process and to choose the right time to purchase. Moreover, consumers' strategic behavior is more complicated on PSSC, and consumers' strategic delayed purchasing behavior will not only reduce the purchase of product under the current price but also cause a reduction in service use, which will inevitably have an impact on product demand and service demand. Therefore, it is necessary to consider consumers' strategic behavior in the relevant research of PSSC.

\section{Problem Description and Model Assumption}

We consider a PSSC consisting of a manufacturer, a service provider, and strategic consumers. In each period, the manufacturer wholesales the product to the service provider, and the service provider not only provides the service that matches the product but also integrates the service and product into PSS to sell to consumers. This paper divides the selling season into $n$ sales periods. Because the sales price of the PSS usually changes within $n$ periods, strategic consumers will not only consider the current sales price when purchasing but also anticipate the sales price in the future. In the period $t(t=1,2, \ldots, n)$, the manufacturer sets the wholesale price of the product $w_{t}$, the service provider sets the price of the PSS $p_{\mathrm{Gt}}$, which is composed of two parts: product price $p_{t}^{p}$ and service price $p_{t}^{s}$; thus, $p_{\mathrm{Gt}}=p_{t}^{p}+p_{t}^{s}$. Each consumer can purchase at most one unit of the PSS during the selling season. The so-called one unit PSS is composed of one unit product and one single-period service. Assuming that the consumer purchases the product-service system in the period $t$, the consumer will continue to purchase and use the service in the remaining sales periods. The above situation is more common in mobile communication. For example, when consumers purchase the mobile phone and communication package service, they usually need to pay for the mobile phone product at a time, while the communication package service fee needs to be paid in periods. As consumers have higher and higher requirements for service quality, the service provider will not only provide basic service quality to meet consumers' basic service requirements but also improve service quality by increasing service investment. The service provider determines service quality $q$ before the start of the sales season and the service cost that the service provider needs to invest $C(q)$. We assume that the service provider's service investment contributes to the improvement of service quality to satisfy the law of diminishing margin, and $C(q)$ is a strictly convex function of $q$, which satisfies the relations $(\mathrm{d} C(q) / \mathrm{d} q)>0$, $\left(\mathrm{d}^{2} \mathrm{C}(q) / \mathrm{d} q^{2}\right)>0$. We use a quadratic convex function to express the service input cost, i.e., $C(q)=\left(k q^{2} / 2\right)$ (e.g., [42]), and $k$ is the service input cost coefficient. The smaller $k$ means the lower the marginal cost of service input, and the higher the efficiency of service input.

The consumers' valuation of the unit PSS is $V$. Since the valuations of different consumers are generally 
heterogeneous in reality, we use the random variable $V$ to represent, the probability density function is $f(v)$, and the cumulative distribution function is $F(v)$. The consumer's valuation of the service in the unit PSS is $\lambda V$, where $\lambda(0<\lambda<1)$ represents the proportion of service valuation (accounts for the valuation of the unit PSS). The larger $\lambda$ means the higher the value of the service in the unit PSS. Let $\mathbf{w}=\left\{w_{1}, w_{2}, \ldots, w_{n}\right\}$ be the vector of wholesale prices during the selling season, $\mathbf{P}^{p}=\left\{p_{1}^{p}, p_{2}^{p}, \ldots, p_{n}^{p}\right\}$ be the vector of product sales prices during the selling season, and $\mathbf{P}^{s}=\left\{p_{1}^{s}, p_{2}^{s}, \ldots, p_{n}^{s}\right\}$ be the vector of service sales prices during the selling season. The utility obtained by the consumer purchasing the PSS in each period is

$$
U_{t}=V-\left(p_{t}^{p}+p_{t}^{s}\right)+q+\sum_{j=t+1}^{n}\left(\lambda V-p_{j}^{s}+q\right), \quad \forall t=1,2, \ldots, n .
$$

Strategic consumers must not only decide whether to purchase the PSS but also at which period to purchase, and they make purchase decision based on the principle of maximizing multiperiod utility. At the determined time for buying the PSS, call it $t_{g}\left(V, \mathbf{P}^{p}, \mathbf{P}^{s}, q\right)$. More specifically, we have

$$
t_{g}\left(V, \mathbf{P}^{p}, \mathbf{P}^{s}, q\right)=\min _{t} \arg \max \left\{U_{t}=V-\left(p_{t}^{p}+p_{t}^{s}\right)+q+\sum_{j=t+1}^{n}\left(\lambda V-p_{j}^{s}+q\right) \mid U_{t} \geq 0\right\} .
$$

Assuming the market size is $N$, the demand for the PSS at each period is

$$
\begin{aligned}
& Q_{t}=N \int_{\Omega_{t}} I_{\left\{t_{g}\left(V, \mathbf{P}^{p}, \mathbf{P}^{s}, q\right)=t\right\}} f(v) \mathrm{d} v, \\
& \Omega_{t}=\left\{v \mid U_{t}(v) \geq\left(U_{j}(v)\right)^{+}, \quad \forall j=1,2, \ldots, n, j \neq t\right\},
\end{aligned}
$$

where $\left(U_{j}(v)\right)^{+}=\max \left\{U_{j}(v), 0\right\}$ and $I_{\{\}}$is an indicator function. Suppose the unit production cost of the product is $c_{m}$. Since the service cost of improving service quality in the early period is relatively large and the service cost in the later period is relatively low, so we can assume the unit cost of the service is zero. Therefore, the optimal decision problem of the manufacturer in $n$ sales periods is

$$
\max _{\mathbf{w}} \Pi_{M}(\mathbf{w})=\sum_{t=1}^{n}\left(\mathbf{w}_{t}-c_{m}\right) Q_{t} .
$$

The optimal decision problem of the service provider is

$$
\begin{aligned}
& \max _{\mathbf{p}^{p}, \mathbf{p}^{s}, q} \Pi_{S}\left(\mathbf{p}^{p}, \mathbf{p}^{s}, q\right) \\
= & \sum_{t=1}^{n}\left(p_{t}^{p}+p_{t}^{s}-w_{t}\right) Q_{t}+\sum_{t=1}^{n}(n-t) p_{t}^{s} Q_{t}-\frac{k}{2} q^{2} .
\end{aligned}
$$

In order to facilitate analysis and obtain some valuable management enlightenment, this paper will analyze and solve the problem of dynamic decision with two-period in the selling season. For ease of illustration, let $p_{1}$ and $p_{2}$ be product sales prices in the first and second periods separately. Let $p_{\mathrm{Gt}}$ be the combination price of PSS. In addition, consider that service prices are more stable relative to product prices in the mobile communication industry. For example, the prices of some new mobile phones are cut shortly after they are launched, and the price of communication package services usually remains unchanged for a long time. So, it is assumed that the service price does not change in the two sales periods, and the service price is represented by $p_{s}$. The condition for consumers to choose to buy at the $i$-th period is $U_{i}\left(V, p_{i}, p_{s}, q\right) \geq$ $\left(U_{3-i}\left(V, p_{3-i}, p_{s}, q\right)\right)^{+},(i=1,2)$. Let $V_{0}$ be the threshold of consumers' strategic delayed purchasing behavior, that is, the critical valuation of consumers buying in the first period or choosing to delay purchase. When $V \geq V_{0}$, consumers buy in the first period. When $V<V_{0}$, consumers do not buy in the first period and delay to the second period to consider whether to buy. The demands for the first and second periods of the PSS are, respectively,

$$
\begin{aligned}
& Q_{1}=N \operatorname{Pr}\left(V-V_{0} \geq 0\right)=N \int_{\left\{v \mid v-V_{0} \geq 0, v \geq 0\right\}} f(v) \mathrm{d} v, \\
& Q_{2}=N \operatorname{Pr}\left(p_{2}+p_{s}-q \leq V<V_{0}\right)=N \int_{\left\{v \mid p_{2}+p_{s}-q \leq v<V_{0}\right\}} f(v) \mathrm{d} v .
\end{aligned}
$$

Without loss of generality, the market size is deterministic and normalized to 1 (e.g., $[8,29,30])$. Consumers' valuations $V$ of the PSS are heterogeneous, and those valuations are distributed uniformly in the interval $\left[0, V_{1}\right]$ (e.g., $[17,28-30]) . V_{1}$ represents the consumers' highest valuation for the PSS. The larger $V_{1}$ means the higher the value of the PSS. The demands for the first and second periods are, respectively,

$$
\begin{aligned}
& Q_{1}=1-\frac{V_{0}}{V_{1}}, \\
& Q_{2}=\frac{V_{0}-p_{2}-p_{s}+q}{V_{1}} .
\end{aligned}
$$

From formulas (7) and (8), when the threshold of consumers' strategic delayed purchasing behavior is larger, the fewer consumers choose to buy in the first period, and the more consumers choose to buy in the second period; it means that consumers are more inclined to delay purchase; that is, the consumers' strategic delayed purchasing behavior 
is more serious. Therefore, let $\Upsilon \equiv V_{0} / V_{1}$ be the intensity of consumers' strategic delayed purchasing behavior, $\Upsilon \in(0,1)$. Add formulas (7) and (8) together, and the total demand in the two-period can be obtained as $Q_{1}+Q_{2}=\left(V_{1}-p_{2}-p_{s}+q\right) / V_{1}$. It can be seen that the total demand in the two-period $\left(Q_{1}+Q_{2}\right)$ is positively related to the quality of service $(q)$ and negatively correlated with the second period PSS portfolio price $\left(p_{2}+p_{s}\right)$. The larger $q$ means the higher the total demand, and the service provider needs to bear higher service input cost, and the lower the price of the second period PSS $\left(p_{2}+p_{s}\right)$, the higher the total demand. In order to ensure that the sales volumes of the two periods are positive and facilitate discussion, we need to assume $k>5 / c_{m}$ and $V_{1}>3 c_{m}+(5 / k)$; that is, the service provider's service investment cost cannot be ignored, and the consumers' highest valuation for the PSS cannot be too low.

In this paper, the superscript " $C$ " means the centralized scenario; the superscript " $D$ " means the decentralized scenario; the superscript "RC" means the coordination scenario under contract design; the superscript asterisk " *" represents the subgame perfect Nash equilibrium strategies; the subscript " $M$ " means the manufacturer; the subscript " $S$ " means the service provider. All the notations are summarized in Table 1.

\section{PSSC under the Centralized Scenario}

Under the centralized supply chain scenario, the manufacturer and the service provider are regarded as an integrated whole, and their common goal is to maximize the profit of the supply chain system. They determine the service quality and the price of the PSS. The total profit function of the system in the two-period is

$$
\pi^{C}=\left(p_{1}^{C}+p_{s}^{C}-c_{m}\right) Q_{1}^{C}+\left(p_{2}^{C}+p_{s}^{C}-c_{m}\right) Q_{2}^{C}+p_{s}^{C} Q_{1}^{C}-\frac{k}{2}\left(q^{C}\right)^{2}
$$

In formula (9), the first and second items on the right side of the equal sign, respectively, represent the profit of the first and second period sales PSS, and the third item represents the service profit generated by consumers who originally purchased in the first period who continue to use the service in the second period. Moreover, the last item represents the service-cost invested in improving service quality. Because the third item depends on the decision of the first period, it is combined with the first item as the supply chain system profit of the first period, and the second item represents the supply chain system profit of the second period. Because of $p_{G 1}^{C}=p_{1}^{C}+2 p_{s}^{C}, p_{G 2}^{C}=p_{2}^{C}+p_{s}^{C}$, therefore, formula (9) is rearranged as follows:

$$
\pi^{C}=\left(p_{G 1}^{C}-c_{m}\right) Q_{1}^{C}+\left(p_{G 2}^{C}-c_{m}\right) Q_{2}^{C}-\frac{k}{2}\left(q^{C}\right)^{2} .
$$

The decision process in the centralized scenario is as follows: (1) the system first decides the service quality and the price of the first period PSS. (2) Consumers decide whether to purchase in the first period or wait for a delayed purchase based on the service quality, the first period combination price, and their expectations of the second period combination price. (3) The system sets the second period combination price. (4) The remaining consumers decide whether to buy or leave in the second period. In this paper, the backward induction method is used to solve the decision problems (see, $[29,30,49]$ ), and the subgame perfect Nash equilibrium between the system and consumers in the centralized scenario is solved in the following order:

$$
\begin{aligned}
p_{G 2}^{C *} & =\arg \max _{p_{G 2}^{C}}\left[\left(p_{G 2}^{C}-c_{m}\right)\left(\frac{V_{0}^{C}}{V_{1}}-\frac{p_{G 2}^{C}-q^{C}}{V_{1}}\right)\right], \\
V_{0}^{C *} & =\inf \left\{V_{0}^{C} \mid(1+\lambda) V_{0}^{C}-p_{G 1}^{C}+2 q^{C} \geq\left(V_{0}^{C}-p_{G 2}^{C *}+q^{C}\right)^{+}\right\}, \\
\left(q^{C *}, p_{G 1}^{C *}\right) & =\arg \max _{q^{C}, p_{G 1}^{C}}\left[\left(p_{G 1}^{C}-c_{m}\right)\left(1-\frac{V_{0}^{C *}}{V_{1}}\right)+\left(p_{G 2}^{C *}-c_{m}\right)\left(\frac{V_{0}^{C *}}{V_{1}}-\frac{p_{G 2}^{C *}-q^{C}}{V_{1}}\right)-\frac{k}{2}\left(q^{C}\right)^{2}\right] .
\end{aligned}
$$

According to formulas (11)-(13), Proposition 1 is as follows.

Proposition 1. Under the centralized supply chain scenario, the optimal combination price of the first period PSS is $p_{G 1}^{C *}=$ $\left(V_{1}(1+2 \lambda)^{2} / 2(1+4 \lambda)\right)+\left(c_{m} / 2\right)+\left(\left((1+8 \lambda)\left(8 \lambda V_{1}-4 \lambda c_{m}\right.\right.\right.$ $\left.\left.\left.+V_{1}-c_{m}\right)\right) /\left(2\left(2 k V_{1}(1+4 \lambda)-4 \lambda-5\right)(1+4 \lambda)\right)\right)$. The optimal service quality is $q^{C *}=\left(V_{1}-c_{m}+4 \lambda\left(2 V_{1}-c_{m}\right)\right)$ / $\left(2 k V_{1}(1+4 \lambda)-4 \lambda-5\right)$. The threshold of consumers' strategic delayed purchasing behavior is $V_{0}^{C *}=$ $\left(V_{1}(1+2 \lambda) /(1+4 \lambda)\right)-\left(2\left(8 \lambda V_{1}-4 \lambda c_{m}+V_{1}-c_{m}\right) /((1+\right.$ $\left.\left.4 \lambda)\left(2 k V_{1}(1+4 \lambda)-4 \lambda-5\right)\right)\right)$. The optimal price of the second period PSS is $p_{G 2}^{C *}=\left(V_{1}(1+2 \lambda) / 2(1+4 \lambda)\right)+\left(c_{m} / 2\right)-((1-$ $4 \lambda)\left(8 \lambda V_{1}-4 \lambda c_{m}+V_{1}-c_{m}\right) /\left(2(1+4 \lambda)\left(2 k V_{1}(1+4 \lambda)-4 \lambda\right.\right.$ $-5))$.

Proposition 1 gives the optimal equilibrium solution of the system under the centralized scenario. It can be seen that when the service input-efficiency is higher, the system will provide higher service quality, while the threshold of consumers' strategic delayed purchasing behavior will decrease, and the system will increase the first period combination 
TABle 1: Notations for the models.

\begin{tabular}{lc}
\hline Notation & Description \\
\hline$V$ & Consumers' valuations of the PSS \\
$c_{m}$ & Unit production cost \\
$k$ & Service input cost coefficient \\
$\lambda$ & The proportion of service valuation (accounts for the valuation of the unit PSS) \\
$Y$ & The intensity of consumers' strategic delayed purchasing behavior \\
$p_{i}^{D}\left(p_{i}^{C}\right)$ & Product sales price in the $i$-th period under the decentralized (centralized) scenario, $i=1,2$ \\
$p_{s}^{D}\left(p_{s}^{C}\right)$ & Service price at each period under the decentralized (centralized) scenario \\
$p_{G i}^{D}\left(p_{G i}^{C}\right)$ & Combination price of PSS in the $i$-th period under the decentralized (centralized) scenario \\
$q^{D}\left(q^{C}\right)$ & Service quality under the decentralized (centralized) scenario \\
$w_{i}^{D}\left(w_{i}^{C}\right)$ & Product wholesale price in the $i$-th period under the decentralized (centralized) scenario \\
$V_{0}^{D}\left(V_{0}^{C}\right)$ & The threshold of consumers' strategic delayed purchasing behavior under the decentralized (centralized) scenario \\
$\varphi_{1}\left(\varphi_{2}\right)$ & The proportion of the service provider's income from the first (second) period of the PSSC \\
$T$ & Transfer payment \\
$\xi$ & The proportion of the manufacturer sharing service-cost
\end{tabular}

price of the PSS and reduce the second period combination price.

Corollary 1. Under the centralized supply chain scenario, the demand for the first period PSS is

$$
Q_{1}^{C *}=\frac{2 \lambda}{1+4 \lambda}+\frac{2\left(8 \lambda V_{1}-4 \lambda c_{m}+V_{1}-c_{m}\right)}{V_{1}(1+4 \lambda)\left(2 k V_{1}(1+4 \lambda)-4 \lambda-5\right)} .
$$

The demand for the second period PSS is

$$
Q_{2}^{C *}=\frac{1+2 \lambda}{2(1+4 \lambda)}-\frac{c_{m}}{2 V_{1}}-\frac{(1-4 \lambda)\left(8 \lambda V_{1}-4 \lambda c_{m}+V_{1}-c_{m}\right)}{2 V_{1}(1+4 \lambda)\left(2 k V_{1}(1+4 \lambda)-4 \lambda-5\right)} \text {. }
$$

The total profit of the system is

$$
\pi^{C *}=\frac{\lambda^{2} V_{1}}{1+4 \lambda}+\frac{\left(V_{1}-c_{m}\right)^{2}}{4 V_{1}}+\frac{\left(8 \lambda V_{1}-4 \lambda c_{m}+V_{1}-c_{m}\right)^{2}}{4 V_{1}(1+4 \lambda)\left(2 k V_{1}(1+4 \lambda)-4 \lambda-5\right)} .
$$

Corollary 1 gives the two-period demands and the total profit of system under centralized supply chain scenario. When the service input-efficiency is lower, the higher the threshold of consumers' strategic delayed purchasing behavior, it means that more consumers are willing to delay purchase, which will make the first period demand lower. Due to lower service input-efficiency, the system will increase the second period combination price to inhibit consumers from delaying purchase. Nevertheless, because consumers are more willing to buy later, it will lead to higher demand in the second period. In addition, the lower the service input-efficiency, the lower the total profit of the system.

\section{PSSC under the Decentralized Scenario}

Under the decentralized supply chain scenario, the manufacturer decides the product wholesale price before the start of each sales period, the service provider decides service quality and PSS combination price. The manufacturer and the service provider make independent decisions with the goal of maximizing their own interests.

The total profit of the manufacturer in the two-period is

$$
\pi_{M}^{D}=\left(w_{1}^{D}-c_{m}\right) Q_{1}^{D}+\left(w_{2}^{D}-c_{m}\right) Q_{2}^{D} .
$$

The total profit of the service provider in the two-period is

$$
\begin{aligned}
\pi_{S}^{D}= & \left(p_{1}^{D}-w_{1}^{D}+p_{s}^{D}\right) Q_{1}^{D}+\left(p_{2}^{D}-w_{2}^{D}+p_{s}^{D}\right) Q_{2}^{D}+p_{s}^{D} Q_{1}^{D} \\
& -\frac{k}{2}\left(q^{D}\right)^{2} .
\end{aligned}
$$

Reorganize formula (18) to get

$$
\pi_{S}^{D}=\left(p_{G 1}^{D}-w_{1}^{D}\right) Q_{1}^{D}+\left(p_{G 2}^{D}-w_{2}^{D}\right) Q_{2}^{D}-\frac{k}{2}\left(q^{D}\right)^{2} .
$$

The decision process of the decentralized scenario is as follows: (1) the manufacturer first sets the first period wholesale price $w_{1}^{D}$. (2) The service provider sets service quality $q^{D}$ and the first period PSS price $p_{G 1}^{D}$. (3) Consumers decide whether to purchase in the first period or wait for a delayed purchase according to the service quality, the first period price, and their expectations of the second period price. (4) The manufacturer sets the second period product wholesale price $w_{2}^{D}$. (5) The service provider sets the second period PSS price $p_{G 2}^{D}$. (6) The remaining consumers decide whether to buy or leave in the second period. Using the backward induction method, the subgame perfect Nash equilibrium between the manufacturer, the service provider, 
and consumers in the decentralized scenario can be solved in the following order:

$$
\begin{aligned}
p_{G 2}^{D *} & =\arg \max _{p_{G 2}^{D}}\left[\left(p_{G 2}^{D}-w_{2}^{D}\right)\left(\frac{V_{0}^{D}}{V_{1}}-\frac{p_{G 2}^{D}-q^{D}}{V_{1}}\right)\right], \\
w_{2}^{D *} & =\arg \max _{w_{2}^{D}}\left[\left(w_{2}^{D}-c_{m}\right)\left(\frac{V_{0}^{D}}{V_{1}}-\frac{p_{G 2}^{D *}-q^{D}}{V_{1}}\right)\right], \\
V_{0}^{D *} & =\inf \left\{V_{0}^{D} \mid(1+\lambda) V_{0}^{D}-p_{G 1}^{D}+2 q^{D} \geq\left(V_{0}^{D}-p_{G 2}^{D *}+q^{D}\right)^{+}\right\}, \\
\left(q^{D *}, p_{G 1}^{D *}\right) & =\arg \max _{q^{D}, p_{G 1}^{D}}\left[\left(p_{G 1}^{D}-w_{1}^{D}\right)\left(1-\frac{V_{0}^{D *}}{V_{1}}\right)+\left(p_{G 2}^{D *}-w_{2}^{D *}\right) \frac{\left(V_{0}^{D *}-p_{G 2}^{D *}+q^{D}\right)}{V_{1}}-\frac{k}{2}\left(q^{D}\right)^{2}\right] . \\
w_{1}^{D *} & =\arg \max _{w_{1}^{D}}\left[\left(w_{1}^{D}-c_{m}\right)\left(1-\frac{V_{0}^{D *}}{V_{1}}\right)+\left(w_{2}^{D *}-c_{m}\right) \frac{\left(V_{0}^{D *}-p_{G 2}^{D *}+q^{D *}\right)}{V_{1}}\right] .
\end{aligned}
$$

From formulas (20)-(24), Proposition 2 is as follows.

Proposition 2. Under the decentralized supply chain scenario, the optimal wholesale prices of the first and second periods are

$$
\begin{aligned}
w_{1}^{D *}= & \frac{\left[\begin{array}{c}
2 k^{2} V_{1}^{3}\left(67+184 \lambda+128 \lambda^{2}\right)+V_{1} A_{1}-c_{m}(61-12 \lambda) \\
-k V_{1}^{2}\left(301-6 k c_{m}(31+48 \lambda)+370 \lambda+64 \lambda^{2}\right)
\end{array}\right]}{4\left(16 k^{2} V_{1}^{2}(5+8 \lambda)-k V_{1}(163+32 \lambda)-2(1-\lambda)\right)}, \\
w_{2}^{D *}= & \frac{\left[\begin{array}{c}
4 k^{2} V_{1}^{3}(17+24 \lambda)+V_{1}\left(7(1-\lambda)-3 k c_{m}(59+16 \lambda)\right) \\
-k V_{1}^{2}\left(149-4 k c_{m}(23+32 \lambda)-44 \lambda\right)-c_{m}(11-4 \lambda)
\end{array}\right]}{2\left(16 k^{2} V_{1}^{2}(5+8 \lambda)-k V_{1}(163+32 \lambda)-2(1-\lambda)\right)} .
\end{aligned}
$$

The optimal service quality is

$q^{D *}=\frac{\left[\begin{array}{c}k V_{1}^{2}(59+136 \lambda)-c_{m}(17-4 \lambda) \\ +V_{1}\left(17(1-\lambda)-k c_{m}(59+32 \lambda)\right)\end{array}\right]}{2\left(16 k^{2} V_{1}^{2}(5+8 \lambda)-k V_{1}(163+32 \lambda)-2(1-\lambda)\right)}$.
The threshold of consumers' strategic delayed purchasing behavior is

$$
V_{0}^{D *}=\frac{\left[\begin{array}{c}
8 k^{2} V_{1}^{3}(17+24 \lambda)-V_{1}\left(3-31 k c_{m}-3 \lambda\right) \\
-3 k V_{1}^{2}\left(119-8 k c_{m}+16 \lambda\right)-c_{m}
\end{array}\right]}{16 k^{2} V_{1}^{2}(5+8 \lambda)-k V_{1}(163+32 \lambda)-2(1-\lambda)} .
$$


The optimal combination prices of the first and second period PSS are

$$
\begin{aligned}
& p_{G 1}^{D *}=\frac{\left[\begin{array}{c}
4 k^{2} V_{1}^{3}(3+4 \lambda)(17+24 \lambda)+V_{1} A_{2}-7 c_{m}(9-2 \lambda) \\
-k V_{1}^{2}\left(329-4 k c_{m}(29+44 \lambda)+310 \lambda+96 \lambda^{2}\right)
\end{array}\right]}{4\left(16 k^{2} V_{1}^{2}(5+8 \lambda)-k V_{1}(163+32 \lambda)-2(1-\lambda)\right)}, \\
& p_{G 2}^{D *}=\frac{\left[\begin{array}{c}
12 k^{2} V_{1}^{3}(17+24 \lambda)+V_{1}\left(21(1-\lambda)-5 k c_{m}(41+16 \lambda)\right) \\
-k V_{1}^{2}\left(447-4 k c_{m}(29+32 \lambda)-132 \lambda\right)-c_{m}(29-8 \lambda)
\end{array}\right]}{4\left(16 k^{2} V_{1}^{2}(5+8 \lambda)-k V_{1}(163+32 \lambda)-2(1-\lambda)\right)} .
\end{aligned}
$$

In addition, $A_{1}=53-k c_{m}(351+28 \lambda)-57 \lambda+4 \lambda^{2}$ and

$$
A_{2}=(1-\lambda)(55-6 \lambda)-k c_{m}(323+82 \lambda) \text {. }
$$

Proposition 2 gives the optimal equilibrium solution under the decentralized supply chain scenario. The equilibrium solutions are all related to service input-efficiency $(k)$, the proportion of service valuation $(\lambda)$, consumers' highest valuation of unit PSS $\left(V_{1}\right)$, and the unit production cost of the product $\left(c_{m}\right)$. When the unit production cost is higher, the manufacturer will increase the wholesale price of the first period product, and the service provider will increase the combination price of the first period PSS and reduce service quality.

Corollary 2. Under the decentralized supply chain scenario, the demands for the first and second period PSS are

$$
\begin{aligned}
& Q_{1}^{D *}=\frac{\left[\begin{array}{c}
8 k^{2} V_{1}^{3}(3+8 \lambda)-V_{1}\left(1+31 k c_{m}-\lambda\right) \\
-k V_{1}^{2}\left(24 k c_{m}+16 \lambda-31\right)+c_{m}
\end{array}\right]}{2 V_{1}\left(16 k^{2} V_{1}^{2}(5+8 \lambda)-k V_{1}(163+32 \lambda)-2(1-\lambda)\right)}, \\
& Q_{2}^{D *}=\frac{\left[\begin{array}{c}
4 k^{2} V_{1}^{3}(17+24 \lambda)+V_{1}\left(7+k c_{m}(149+16 \lambda)-7 \lambda\right) \\
-k V_{1}^{2}\left(149+4 k c_{m}(17+32 \lambda)-44 \lambda\right)-7 c_{m}
\end{array}\right]}{4 V_{1}\left(16 k^{2} V_{1}^{2}(5+8 \lambda)-k V_{1}(163+32 \lambda)-2(1-\lambda)\right)} .
\end{aligned}
$$

The total profits of the service provider and the manufacturer are

$$
\begin{gathered}
\pi_{S}^{D *}=\frac{\left[\begin{array}{c}
4 \lambda^{3} V_{1}^{2}\left(8 k V_{1}-1\right)^{4}+B_{1} \lambda^{2} V_{1}\left(8 k V_{1}-1\right)^{2} \\
+2 B_{2} \lambda\left(V_{1}-c_{m}\right)+B_{3}\left(V_{1}-c_{m}\right)^{2}
\end{array}\right]}{16 V_{1}\left(16 k^{2} V_{1}^{2}(5+8 \lambda)-k V_{1}(163+32 \lambda)-2(1-\lambda)\right)^{2}}, \\
\pi_{M}^{D *}=\frac{\left[\begin{array}{c}
\lambda^{2} V_{1}^{2}\left(8 k V_{1}-1\right)+\left(V_{1}-c_{m}\right)^{2}\left(49 k^{2} V_{1}^{2}-46 k V_{1}+1\right)^{2} \\
+2 \lambda V_{1}\left(V_{1}-c_{m}\right)\left(56 k^{2} V_{1}^{2}-32 k^{2} c_{m} V_{1}+31 k V_{1}-1\right)
\end{array}\right]}{4 V_{1}\left(16 k^{2} V_{1}^{2}(5+8 \lambda)-k V_{1}(163+32 \lambda)-2(1-\lambda)\right)} .
\end{gathered}
$$

In addition,

$$
\begin{aligned}
B_{1}= & 624 k^{2} V_{1}^{3}-2 k V_{1}^{2}\left(352 k c_{m}+83\right)-32 k c_{m}^{2}+8 c_{m} \\
& +V_{1}\left(256 k^{2} c_{m}^{2}-184 k c_{m}+37\right), \\
B_{2}= & 15616 k^{4} V_{1}^{5}-32 k^{3} V_{1}^{4}\left(356 k c_{m}+715\right)+V_{1}\left(92 k c_{m}-43\right) \\
& -k V_{1}^{2}\left(4178 k c_{m}-1685\right)+8 k^{2} V_{1}^{3}\left(2396 k c_{m}-845\right)-2 c_{m}, \\
B_{3}= & 7984 k^{4} V_{1}^{4}-24230 k^{3} V_{1}^{3}+17361 k^{2} V_{1}^{2}-2484 k V_{1}+45 .
\end{aligned}
$$

\section{Comparative Analysis of Two PSSC Scenarios}

According to the equilibrium results given by Propositions 1 and 2 and Corollaries 1 and 2, comparing and analyzing the intensity of consumers' strategic delayed purchasing behavior, service quality, PSS combination prices, PSS demands, and PSSC performance under the centralized and decentralized scenarios, we reveal the problem of decision bias and system profit loss under the decentralized scenario. 
Proposition 3. The intensity of consumers' strategic delayed purchasing behavior under the two scenarios has the following relationships:

(1) $\Upsilon^{D *}<\Upsilon^{C *}$ if and only if $0<\lambda<\lambda_{a}$, otherwise $\Upsilon^{D *} \geq \Upsilon^{C *}$

(2) $\left(\partial \Upsilon^{C *} / \partial \lambda\right)<\left(\partial \Upsilon^{D *} / \partial \lambda\right)<0, \quad\left(\partial \Upsilon^{C *} / \partial k\right)>\left(\partial \Upsilon^{D *} /\right.$ $\partial k)>0,\left(\partial Y^{C *} / \partial V_{1}\right)>0>\left(\partial Y^{D *} / \partial V_{1}\right)$,

where

$$
\begin{aligned}
\lambda_{a}= & \frac{\left[\begin{array}{c}
16 c_{m}^{2}\left(48 k^{3} V_{1}^{3}-90 k^{2} V_{1}^{2}-k V_{1}-1\right)^{2} \\
+8 E_{1} c_{m} V_{1}+E_{2} V_{1}^{2}
\end{array}\right]^{1 / 2}-E_{3}}{8 V_{1}\left(2 k V_{1}-1\right)\left(8 k V_{1}-1\right)^{2}}, \\
E_{1}= & 3072 k^{6} V_{1}^{6}+33408 k^{5} V_{1}^{5}-92480 k^{4} V_{1}^{4}+56604 k^{3} V_{1}^{3} \\
& -17256 k^{2} V_{1}^{2}-53 k V_{1}+9, \\
E_{2}= & 200704 k^{6} V_{1}^{6}-1431552 k^{5} V_{1}^{5}+2797056 k^{4} V_{1}^{4} \\
& -1850240 k^{3} V_{1}^{3}+408996 k^{2} V_{1}^{2}+14796 k V_{1}+81, \\
E_{3}= & 320 k^{3} V_{1}^{4}+48 k^{2} V_{1}^{3}\left(4 k c_{m}-19\right)-V_{1}\left(4 k c_{m}-17\right) \\
& -18 k V_{1}^{2}\left(20 k c_{m}-31\right)-4 c_{m} .
\end{aligned}
$$

From Proposition 3, when the proportion of service valuation is relatively high (low), the intensity of consumers' strategic delayed purchasing behavior under the decentralized scenario is stronger (weaker) than centralized scenario, which means that consumers are more inclined to wait for a delayed purchase under the decentralized (centralized) scenario. As the proportion of service valuation increases, the intensity of consumers' strategic delayed purchasing behavior will gradually decrease, which shows that the proportion of service valuation can alleviate consumers' strategic purchasing behavior under the two scenarios. Compared with the centralized scenario, the change in the proportion of service valuation causes a smaller change in the intensity of consumers' strategic delayed purchasing behavior under the decentralized scenario, which means that the proportion of service valuation has a weaker inhibitory effect on consumers' strategic purchasing behavior under the decentralized scenario. Moreover, the service provider improves service input-efficiency which will reduce the intensity of consumers' strategic delayed purchasing behavior under the two scenarios, and the inhibitory effect on the intensity of consumers' strategic delayed purchasing behavior is more obvious under the centralized scenario. When consumers' highest valuation of the PSS is higher, the intensity of consumers' strategic delayed purchasing behavior is weaker (stronger) under the decentralized (centralized) scenario, which means that the value of the PSS will inhibit (promote) consumers' strategic purchase behavior under the decentralized (centralized) scenario.
Proposition 4. The equilibrium results under the two scenarios have the following relationships:

(1) $q^{D *}<q^{C *}, p_{G 1}^{D *}>p_{G 1}^{C *}, p_{G 2}^{D *}>p_{G 2}^{C *}$;

(2) $Q_{1}^{D *}>Q_{1}^{C *}$ if and only if $0<\lambda<\lambda_{a}$, otherwise $Q_{1}^{D *} \leq Q_{1}^{C *} ; Q_{2}^{D *}<Q_{2}^{C *} ; Q_{1}^{D *}+Q_{2}^{D *}<Q_{1}^{C *}+Q_{2}^{C *} ;$

(3) Let $\eta=\left(\pi^{C *}-\left(\pi_{M}^{D *}+\pi_{S}^{D *}\right)\right) / \pi^{C *}$, which indicates the loss rate of system profit in the two-period of the PSSC, where $0<\eta<1$.

In addition, $\lambda_{a}$ is shown in Proposition 3.

Proposition 4 shows the following: (1) under the decentralized scenario, the optimal service quality is lower than that under the centralized scenario, and the prices of the PSS are higher than those under the centralized scenario, which means that the service utility and the net utility of the PSS are lower under the decentralized scenario than those under the centralized scenario. (2) When the proportion of service valuation is relatively high, according to Proposition 3, it can be seen that the intensity of consumers' strategic delayed purchasing behavior under the decentralized scenario is stronger than that under the centralized scenario. Therefore, the first period demand under the centralized scenario is greater than that under the decentralized scenario. When the proportion of service valuation is relatively low, consumers' strategic purchasing behavior is more obvious under the centralized scenario, so the first period demand under the decentralized scenario is greater than that under the centralized scenario. Compared with the centralized scenario, the service quality is lower and the price of the second PSS is higher under the decentralized scenario, which means that consumers have a higher purchase threshold of the second period under the decentralized scenario, which leads to the demand of the second period PSS which is less under the decentralized scenario. In addition, because the total demand is negatively correlated with the second period purchase threshold, the total demand in the two-period is less than that under the centralized scenario. (3) The manufacturer and service provider make decisions based on their own interests under the decentralized scenario, which will lead to double marginalization, causing a decrease in the optimal service quality, and PSS prices increase and total demand decreases. As a result, the total profit of the supply chain system under the decentralized scenario is lower than that under the centralized scenario; that is, the efficiency of the supply chain system decreases.

Proposition 5. The influence of the proportion of service valuation on the deviation of equilibrium results under two scenarios:

(1) $\left(\partial\left(q^{C *}-q^{D *}\right) / \partial \lambda\right)>0,\left(\partial^{2}\left(q^{C *}-q^{D *}\right) / \partial \lambda^{2}\right)<0, \quad\left(\partial^{2}\right.$ $\left.\left(q^{C *}-q^{D *}\right) / \partial \lambda \partial k\right)<0$;

(2) $\left(\partial\left(p_{G 1}^{D *}-p_{G 1}^{C *}\right) / \partial \lambda\right)>0, \quad\left(\partial^{2}\left(p_{G 1}^{D *}-p_{G 1}^{C *}\right) / \partial \lambda^{2}\right)<0$, $\left(\partial^{2}\left(p_{G 1}^{D *}-p_{G 1}^{C *}\right) / \partial \lambda \partial k\right)>0$;

(3) $\left(\partial\left(p_{G 2}^{D *}-p_{G 2}^{C *}\right) / \partial \lambda\right)>0,\left(\partial^{2}\left(p_{G 2}^{D *}-p_{G 2}^{C *}\right) / \partial \lambda^{2}\right)<0$;

(4) When $k>\Delta_{g} / c_{m}, \quad V_{1}<V_{g}$ and $0<\lambda<\lambda_{g}$, $\left(\partial^{2}\left(p_{G 2}^{D *}-p_{G 2}^{C *}\right) / \partial \lambda \partial k\right)<0$; when $k \leq \Delta_{g} / c_{m}$, or 

$k>\Delta_{g} / c_{m}$ and $V_{1} \geq V_{g}$, or $k>\Delta_{g} / c_{m}, V_{1}<V_{g}$ and
$\lambda_{g} \leq \lambda<1, \quad\left(\partial^{2}\left(p_{G 2}^{D *}-p_{G 2}^{C *}\right) / \partial \lambda \partial k\right) \geq 0$,

where

$$
\begin{aligned}
& \Delta_{g}=\{\Delta>0 \mid G(\Delta)=0\} \approx 46.6753, \\
& V_{g}=\left\{V_{1}>3 c_{m}+\frac{5}{k} \mid L\left(V_{1}\right)=0\right\} . \\
& \lambda_{g} \text { fits }\left.\left(\partial^{2}\left(p_{G 2}^{D *}-p_{G 2}^{C *}\right) / \partial \lambda \partial k\right)\right|_{\lambda=\lambda_{g}}=0, \\
& L\left(V_{1}\right)=6885376 k^{7} V_{1}^{5}-256 k^{6} V_{1}^{7}\left(87776 k c_{m}-50343\right) \\
&+2560 k^{5} V_{1}^{6}\left(48046 k c_{m}-103527\right) \\
&-8 k^{4} V_{1}^{5}\left(23284128 k c_{m}-90912755\right) \\
&-4 k^{3} V_{1}^{4}\left(6235172 k c_{m}+181344681\right) \\
&+2 k^{2} V_{1}^{3}\left(105348380 k c_{m}+147699033\right) \\
&-k V_{1}^{2}\left(102668604 k c_{m}+118369519\right) \\
&+ V_{1}\left(43205570 k c_{m}+1180866\right)-2127256 c_{m}, \\
& G(\Delta)=-3968372736 \Delta^{8}+146844907776 \Delta^{7} \\
&+ 1633928951808 \Delta^{6}+6994653963192 \Delta^{5} \\
&+ 16096435123356 \Delta^{4}+21785841003186 \Delta^{3} \\
&+ 17409073383429 \Delta^{2}+7616922711372 \Delta \\
&+ 1408808597105 .
\end{aligned}
$$

From Proposition 5, (1) when the proportion of service valuation is higher, the difference in service quality between centralized scenario and decentralized scenario is greater. As the proportion of service valuation increases, the service provider is willing to improve service quality under the two scenarios. In addition, the high proportion of service valuation will cause the manufacturer to increase the wholesale price in the first period under the decentralized scenario, which will inhibit the service provider from improving service quality, and make the service quality increase less than that under the centralized scenario. That is, the difference in service quality under the two scenarios will aggravate as the proportion of service valuation increases, and this degree of aggravation will gradually weaken. The service provider improves the service inputefficiency which will intensify the role of the proportion of service valuation in promoting the expansion of service quality gap between the two scenarios. (2) (3) The higher the proportion of service valuation, the greater the price difference between the first and second periods of the two scenarios. As the proportion of service valuation increases, the intensity of consumers' strategic delayed purchasing behavior decreases, which means that the demand in the first period increases. Meanwhile, the manufacturer will increase the wholesale price of the first period product to obtain more profit, and the service provider faces high service cost and high wholesale prices will increase the price of the first period PSS, which leads to price distortion of the first period PSS under the decentralized scenario. As the proportion of service valuation increases, price distortion will aggravate and the degree of aggravation will gradually decrease. The service provider improves service input-efficiency which will inhibit the promotion effect of the proportion of service valuation to price difference of the first period under the two scenarios, which means that the higher the efficiency of service input, and as the proportion of service valuation increases, the degree of increase in the first period price difference gradually decreases. The higher proportion of service valuation will lead to more consumers buying in the first period, and in order to attract surplus consumers to purchase in the second period, both the manufacturer and the service provider will lower the second period price. However, due to the influence of wholesale price, the service provider' pricing in the second period is higher than that under the centralized scenario, leading to price distortion in the second period, and as the proportion of service valuation increases, the price distortion will aggravate and show a trend of decreasing marginal. (4) The impact of service input-efficiency on the change in the second period price difference with the proportion of service valuation is related to the value of the PSS, the proportion of service valuation, and the efficiency of service input. When the service input-efficiency is high, or the service input-efficiency is low and the PSS value is high, the higher the service input-efficiency, the more it can alleviate the promotion effect of the proportion of service valuation to price difference of the second period. Moreover, when service input-efficiency is low, PSS value is low, and the proportion of service valuation is relatively high (low), the lower the efficiency of service input, the more it can facilitate (alleviate) the promotion effect of the proportion of service valuation to price difference of the second period.

From Propositions 3 5, it can be seen that the optimal service quality and the PSS prices under the decentralized scenario deviate from the optimal scenario of the system. As the proportion of service valuation increases, this degree of deviation will increase. Especially, when the proportion of service valuation is relatively high, the intensity of consumers' strategic delayed purchasing behavior under the decentralized scenario is higher than that under the centralized scenario, which shows that consumers are more inclined to wait for delayed purchase under the decentralized scenario. Therefore, in order to improve the performance of the supply chain system under the decentralized scenario, the two-period prices can be adjusted to ease the consumers' strategic purchasing behavior and encourage more consumers to purchase in the first period. Aiming at the problem of decision bias under the decentralized scenario, we will design the "two-period revenue sharing + service-cost sharing" combined contract mechanism to coordinate the decision behaviors of supply chain members and influence consumers' strategic purchasing behavior, and ultimately realize the optimal performance of the PSSC. 


\section{7. “Two-Period Revenue Sharing + Service-Cost Sharing" Combined Dynamic Contract}

This section adopts the combined dynamic contract of "twoperiod revenue sharing + service-cost sharing" $\left\{w_{1}, w_{2}, \varphi_{1}, \varphi_{2}, \xi\right\}$ to coordinate decision behaviors of the manufacturer and the service provider under the decentralized scenario. $\varphi_{1}$ and $\varphi_{2}$, respectively, represent the proportion of the service provider's income from the first period and the second period of the PSSC, where $\varphi_{1}, \varphi_{2} \in(0,1)$. Therefore, $1-\varphi_{1}$ and $1-\varphi_{2}$, respectively, represent the proportion of the manufacturer's revenue in the two-period. $\xi$ represents the proportion of the manufacturer sharing service cost, where $\xi \in(0,1)$. Under the "two-period revenue sharing + service-cost sharing" combined contract, the service provider's two-period profit function is

$$
\pi_{S}^{\mathrm{RC}}=\left(\varphi_{1} p_{G 1}-w_{1}\right) Q_{1}+\left(\varphi_{2} p_{G 2}-w_{2}\right) Q_{2}-(1-\xi) \frac{k}{2} q^{2} .
$$

The manufacturer's two-period profit function is

$$
\begin{aligned}
\pi_{M}^{\mathrm{RC}}= & \left(w_{1}-c_{m}+\left(1-\varphi_{1}\right) p_{G 1}\right) Q_{1} \\
& +\left(w_{2}-c_{m}+\left(1-\varphi_{2}\right) p_{G 2}\right) Q_{2}-\xi \frac{k}{2} q^{2} .
\end{aligned}
$$

Proposition 6. Under the decentralized scenario, the "twoperiod revenue sharing + service-cost sharing" combined $d y$ namic contract given by the manufacturer can coordinate the PSSC, and the contract parameters need to meet the following conditions:

$$
\begin{aligned}
& \text { (1) } w_{1}^{R C}=\left(k V_{1}^{2} \alpha_{1}+V_{1} \alpha_{2}-c_{m}\left(\varphi_{1}(3+4 \lambda)+6 \varphi_{2}\right)\right) / \\
& \left.V_{1}(1+4 \lambda)-4 \lambda-5\right) ; \\
& \text { (2) } w_{2}^{R C}=\varphi_{2} c_{m} ; \\
& \text { (3) } \xi=\left(k V_{1}^{2} \alpha_{3}+k c_{m} V_{1}\left(2 \varphi_{2}-1\right)(1+4 \lambda)+2 \alpha_{4}\right) / k V_{1} \\
& \quad\left(V_{1}(1+8 \lambda)-c_{m}(1+4 \lambda)\right) ; \\
& \text { (4) } 0<\varphi_{2}<\lambda \varphi_{1} ; \\
& \text { (5) } \varphi_{1}^{2}<2 k V_{1}(1-\xi)\left(\lambda \varphi_{1}-\varphi_{2}\right)+4 \varphi_{1} \varphi_{2}(1-\lambda),
\end{aligned}
$$

where

$$
\begin{aligned}
& \alpha_{1}=\varphi_{1}-2 \varphi_{2}+4 \lambda\left(\varphi_{1}-\varphi_{2}\right), \\
& \alpha_{2}=k c_{m}(1+4 \lambda)\left(\varphi_{1}+2 \varphi_{2}\right)+2(1-\lambda)\left(3 \varphi_{2}-\varphi_{1}\right), \\
& \alpha_{3}=1-2 \varphi_{2}+4 \lambda\left(2-\varphi_{1}-\varphi_{2}\right), \\
& \alpha_{4}=\left(3 \varphi_{2}-\varphi_{1}\right)\left(V_{1}(1-\lambda)-c_{m}\right) .
\end{aligned}
$$

From the analysis of Proposition 6, it can be found that the design of reasonable revenue sharing ratio and cost sharing ratio can make the decision of supply chain members consistent with the optimal decision of the system. Under the combined dynamic contract designed by the manufacturer, when the two-period revenue sharing ratio and service-cost sharing ratio meet certain conditions, the profit loss of the supply chain system under the decentralized scenario will be eliminated, and the optimal profit of the supply chain system will be achieved. According to the conditions satisfied by the coordination contract parameters, the service provider's supply chain revenue sharing ratio $\varphi_{2}$ in the second period is lower than the first period sharing ratio $\varphi_{1}$. In addition, the first period wholesale price of the manufacturer under contract coordination is related to the first and second period revenue sharing ratios $\varphi_{1}$ and $\varphi_{2}$. The establishment of the second period wholesale price has nothing to do with the first period revenue sharing ratio $\varphi_{1}$ but is related to the second period revenue sharing ratio $\varphi_{2}$. The service-cost sharing ratio $\xi$ is related to the first and second period revenue sharing ratios $\varphi_{1}$ and $\varphi_{2}$ and service input-efficiency $k$. We can get the following propositions through further analysis.

\section{Proposition 7}

(1) $\left(\partial w_{1}^{R C} / \partial \varphi_{1}\right)>0, \quad\left(\partial w_{1}^{R C} / \partial \varphi_{2}\right)<0, \quad\left(\partial w_{2}^{R C} / \partial \varphi_{1}\right)=0$, $\left(\partial w_{2}^{R C} / \partial \varphi_{2}\right)>0$

(2) $\left(\partial \xi / \partial \varphi_{1}\right)<0,\left(\partial \xi / \partial \varphi_{2}\right)<0$;

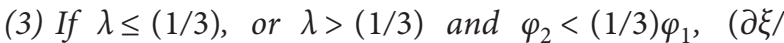
$\partial \lambda)<0$; if $\lambda>(1 / 3)$ and $\varphi_{2} \geq(1 / 3) \varphi_{1},(\partial \xi / \partial \lambda) \geq 0$;

(4) If $\lambda \leq(1 / 3)$, or $(1 / 3)<\lambda \leq 1-\left(c_{m} / V_{1}\right)$ and $\varphi_{2} \leq$


$\partial k) \geq 0$; if $(1 / 3)<\lambda<1-\left(c_{m} / V_{1}\right)$ and $\varphi_{2}>(1 / 3) \varphi_{1}$, or $\lambda>1-\left(c_{m} / V_{1}\right)$ and $\varphi_{2}<(1 / 3) \varphi_{1},(\partial \xi / \partial k)<0$.

Proposition 7 shows that when the first and second period revenue sharing ratios $\varphi_{1}$ and $\varphi_{2}$ are higher, the manufacturer will increase the first and second period wholesale prices. Because when the service provider accounts for a higher proportion of profits in the first and second periods of the supply chain system, which means that the manufacturer has a lower proportion of profits, the manufacturer will increase its profits by increasing wholesale prices. When the second period revenue sharing ratio $\varphi_{2}$ is high, the manufacturer will lower the first period wholesale price. The establishment of the wholesale price of the service provider in the second period has nothing to do with the revenue sharing ratio $\varphi_{1}$ in the first period. When the first and second period revenue sharing ratios $\varphi_{1}$ and $\varphi_{2}$ are higher, the manufacturer will reduce the service-cost sharing ratio $\xi$; that is, when the manufacturer has a low proportion of profits in the first and second periods of the supply chain system, the manufacturer will reduce sharing ratio of the service cost. The effect of the service provider's service inputefficiency $k$ on the manufacturer's service-cost ratio $\xi$ is related to the proportion of service valuation $\lambda$ and the second period revenue sharing ratio $\varphi_{2}$. When the proportion of service valuation is relatively low, the lower the service input-efficiency (that is, the larger the $k$ ), the higher the manufacturer's service-cost sharing ratio. When the proportion of service valuation is medium (high), with the increase in the revenue sharing proportion in the second 
period, the service input-efficiency will first have a negative (positive) influence on the manufacturer's service-cost sharing proportion and then a positive (negative) influence.

In Proposition 6, the service provider can increase service input to improve service quality and reduce the sale prices of the two-period PSS under the implementation of combined dynamic contract, which will achieve the optimal supply chain system under the centralized scenario. However, due to the establishment of higher or lower system revenue sharing ratios $\varphi_{1}$ and $\varphi_{2}$, the manufacturer or service provider may be reluctant to participate in the contract. Therefore, the designed "two-period revenue sharing + service-cost sharing" combined dynamic contract not only needs to be able to coordinate the PSSC but also needs to enable both the manufacturer and the service provider to achieve Pareto improvement. Thus, Proposition 8 gives new conditions for the combined dynamic contract to achieve perfect coordination of the PSSC.

Proposition 8. Under the "two-period revenue sharing + service-cost sharing" combined dynamic contract, when the revenue sharing ratios $\varphi_{1}$ and $\varphi_{2}$ of the first and second periods need to meet the following conditions:

$$
\left\{\begin{array}{l}
0<\varphi_{2}<\lambda \varphi_{1}, \\
\varphi_{1}^{2}<2 k V_{1}(1-\xi)\left(\lambda \varphi_{1}-\varphi_{2}\right)+4 \varphi_{1} \varphi_{2}(1-\lambda), \\
\frac{F^{2} \Theta}{16 K_{0}^{2} K_{1} K_{2}}-\Psi \varphi_{1} \leq \varphi_{2} \leq \frac{F \Omega}{4 K_{0} K_{1} K_{2}}-\Psi \varphi_{1} .
\end{array}\right.
$$

If and only if $\lambda_{r}<\lambda<1$ and revenue sharing ratios $\varphi_{1}$ and $\varphi_{2}$ satisfy formula (39), both the manufacturer and the service provider can achieve Pareto improvement, that is, perfect coordination of the PSSC. When $0<\lambda \leq \lambda_{r}$, formula (39) has no solution, which indicates that the combined dynamic contract cannot achieve perfect coordination, where

$$
\begin{aligned}
\lambda_{r}= & \left\{0<\lambda<1 \mid F^{2} \Theta-16 K_{0}^{2} K_{1} K_{2}(\lambda+\Psi)=0\right\}, \\
K_{0}= & 16 k^{2} V_{1}^{2}(5+8 \lambda)-k V_{1}(163+32 \lambda)-2+2 \lambda, \\
K_{1}= & k V_{1}^{2}(1+10 \lambda)-V_{1}\left(k c_{m}(1+4 \lambda)+9 \lambda\right)+4 \lambda c_{m}, \\
K_{2}= & k V_{1}^{2}(1+2 \lambda)-V_{1}\left(k c_{m}(1+4 \lambda)-3 \lambda+3\right)+3 c_{m}, \\
F= & 2 k V_{1}(1+4 \lambda)-4 \lambda-5, \\
& \left(2 k \lambda V_{1}^{2}-\lambda V_{1}+V_{1}-c_{m}\right)\left(8 k \lambda^{2} V_{1}^{2}-V_{1}(2 \lambda+1)^{2}+c_{m}\right), \\
\Psi= & K_{1} K_{2} \\
\Omega= & 4 \lambda^{3} V_{1}^{2}\left(2 k V_{1}-1\right)\left(8 k V_{1}-1\right)^{2}+K_{3} \lambda^{2} V_{1}+2 K_{4} \lambda\left(V_{1}-c_{m}\right) \\
& +\left(V_{1}-c_{m}\right)^{2}\left(62 k^{3} V_{1}^{3}-309 k^{2} V_{1}^{2}+416 k V_{1}+13\right), \\
\Theta= & 4 \lambda^{3} V_{1}^{2}\left(8 k V_{1}-1\right)^{4}+K_{5} \lambda^{2} V_{1}\left(8 k V_{1}-1\right)^{2} \\
& +2 K_{6} \lambda\left(V_{1}-c_{m}\right)+K_{7}\left(V_{1}-c_{m}\right)^{2} .
\end{aligned}
$$

$\xi$ is shown in Proposition 6. In addition, 


$$
\begin{aligned}
K_{3}= & 128 k^{3} V_{1}^{2}\left(5 V_{1}\left(V_{1}-c_{m}\right)+4 c_{m}^{2}\right)-24 k^{2} V_{1}^{2}\left(23 V_{1}+30 c_{m}\right) \\
& +k\left(578 V_{1}^{2}-40 c_{m} V_{1}+16 c_{m}^{2}\right)+21 V_{1}-8 c_{m}, \\
K_{4}= & 2\left(V_{1}-c_{m}\right)\left[\begin{array}{c}
4 k^{3} V_{1}^{3}\left(35 V_{1}-47 c_{m}\right)-k V_{1}\left(533 V_{1}-38 c_{m}\right) \\
-6 k^{2} V_{1}^{2}\left(20 V_{1}-83 c_{m}\right)-15 V_{1}+2 c_{m}
\end{array}\right], \\
K_{5}= & 16 k^{2} V_{1}\left(39 V_{1}^{2}-44 V_{1} c_{m}+16 c_{m}^{2}\right) \\
& -2 k\left(83 V_{1}^{2}+92 V_{1} c_{m}+16 c_{m}^{2}\right)+37 V_{1}+8 c_{m}, \\
K_{6}= & k V_{1}\left(1685 V_{1}+92 c_{m}\right)-2 k^{2} V_{1}^{2}\left(3380 V_{1}+2089 c_{m}\right)-2 c_{m} \\
& +128 k^{4} V_{1}^{4}\left(122 V_{1}-89 c_{m}\right)-32 k^{3} V_{1}^{3}\left(715 V_{1}-599 c_{m}\right)-43 V_{1}, \\
K_{7}= & 45+k V_{1}\left(7984 k^{3} V_{1}^{3}-24230 k^{2} V_{1}^{2}+17361 k V_{1}-2484\right) .
\end{aligned}
$$

Proposition 8 shows that if and only if the service value is relatively high $\left(\lambda>\lambda_{r}\right)$ and the two-period system revenue sharing ratios satisfy the conditions given in formula (39), the "two-period revenue sharing + service-cost sharing" contract can achieve perfect coordination of the PSCC. It can be seen from the certification process that when the proportion of service valuation is relatively high, there will be $\Psi>0$; from a condition $\varphi_{2} \in\left[\left(F^{2} \Theta / 16 K_{0}^{2} K_{1} K_{2}\right)-\Psi \varphi_{1}\right.$, $\left(F \Omega / 4 K_{0} K_{1} K_{2}\right)-\Psi \varphi_{1}$ ] given by formula (39), it can be seen that when $\varphi_{1}$ is larger, the upper and lower bounds of possible values of $\varphi_{2}$ become smaller. When the proportion of service valuation is relatively low $\left(\lambda \leq \lambda_{r}\right)$, there will be $\left(F^{2} \Theta / 16 K_{0}^{2} K_{1} K_{2}\right)-\Psi \varphi_{1} \geq \lambda \varphi_{1}$, which leads to formula (39) without solution; that is, it is impossible to guarantee that the service provider has both the optimal solution and the Pareto improvement under the contract coordination, and the service provider is unwilling to participate in the contract. Therefore, in the case of $\lambda \leq \lambda_{r}$, the contract cannot achieve perfect coordination. In order to enable the service provider to participate in the contract, the manufacturer will provide the service provider with a transfer payment $T$ as a compensation, enabling the service provider to achieve Pareto improvement.

Proposition 9. When $0<\lambda \leq \lambda_{r}$, under the "two-period revenue sharing + service-cost sharing + transfer payment" new combined dynamic contract, the first and second period revenue sharing ratios $\varphi_{1}$ and $\varphi_{2}$ and transfer payment $T$ meet the following conditions:

$$
\left\{\begin{array}{l}
0<\varphi_{2}<\lambda \varphi_{1} \\
\varphi_{1}^{2}<2 k V_{1}(1-\xi)\left(\lambda \varphi_{1}-\varphi_{2}\right)+4 \varphi_{1} \varphi_{2}(1-\lambda), \\
T \in\left[\pi_{S}^{D *}-\pi_{S}^{\mathrm{RC}}, \pi_{M}^{\mathrm{RC}}-\pi_{M}^{D *}\right] .
\end{array}\right.
$$

This contract can enable the manufacturer and the service provider to achieve Pareto improvement, that is, to achieve perfect coordination of the PSSC, where

$$
\begin{aligned}
& \pi_{S}^{\mathrm{RC}}=\frac{\left(\begin{array}{c}
\varphi_{1}\left(2 k \lambda V_{1}^{2}-\lambda V_{1}+V_{1}-c_{m}\right) \\
\times\left(8 k \lambda^{2} V_{1}^{2}-V_{1}(1+2 \lambda)^{2}+c_{m}\right)+\varphi_{2} K_{1} K_{2}
\end{array}\right)}{\left(V_{1} F^{2}\right)}, \\
& \pi_{M}^{\mathrm{RC}}=\pi^{C *}-\pi_{S}^{\mathrm{RC}} .
\end{aligned}
$$

In addition, $F, K_{1}$, and $K_{2}$ are shown in Proposition 8, and $\pi^{C *}$ is shown in Corollary 1 .

Proposition 9 indicates that when the proportion of service valuation is relatively small, the "two-period revenue sharing + service-cost sharing + transfer payment" contract can encourage the service provider to participate in the contract and realize the Pareto improvement. In addition to meeting the requirements of formula (42), the value of revenue sharing ratios $\varphi_{1}$ and $\varphi_{2}$ and transfer payment $T$ in the two-period system is also related to the bargaining power between the manufacturer and the service provider.

\section{Numerical Simulation}

Based on the propositions derived from the above theoretical analysis, this section provides intuitive results and verifications through numerical simulation to get more management enlightenment. Let $c_{m}=150, V_{1}=600, \lambda=1 / 10$, and $k=1$. First, analyze the impact of service input-efficiency $k$ and the proportion of service valuation $\lambda$ on the intensity of consumers' strategic delayed purchasing behavior $\Upsilon^{C^{\prime \prime} *}$ and $\Upsilon^{D \text { "* }}$ under the two scenarios, as shown in Figure 1.

From Figure 1(a), it can be seen that the lower the service input-efficiency (that is, the larger $k$ ), the higher the intensity of consumers' strategic delayed purchasing behavior in both decentralized and centralized scenarios, and the relatively higher decentralized scenario. This indicates that if the service provider improves the service input-efficiency, which will reduce the intensity of consumers' strategic delayed purchasing behavior and promote more consumers to 


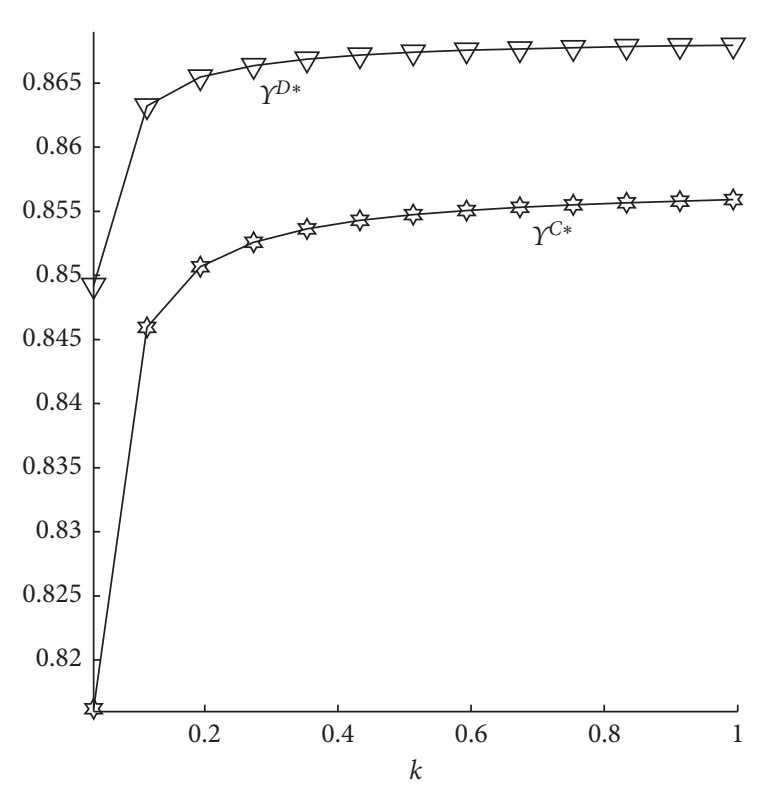

(a)

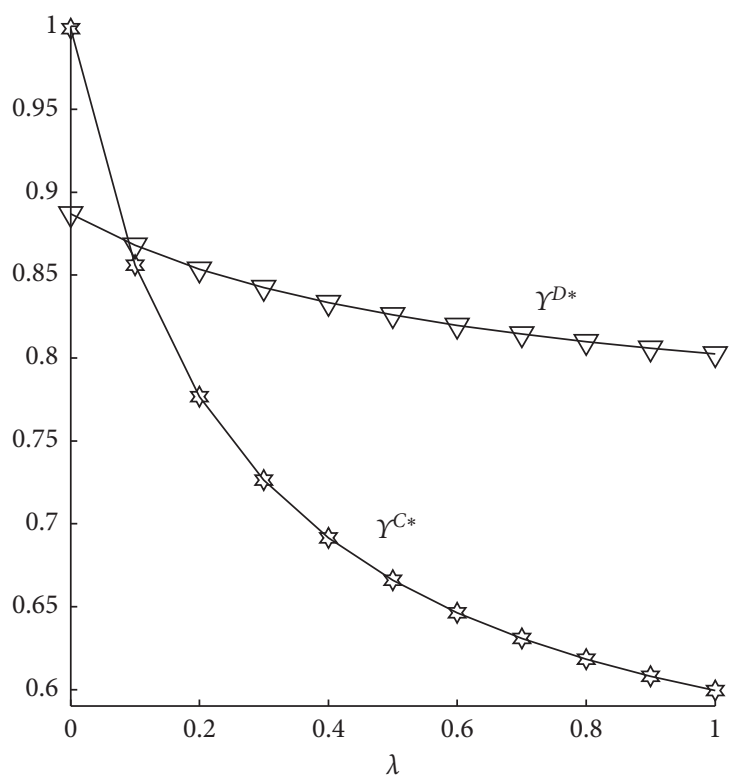

(b)

Figure 1: The impact of $k$ and $\lambda$ on $\Upsilon^{C *}$ and $\Upsilon^{D *}$.

choose to purchase in the first period. In addition, compared with decentralized scenario, under the centralized scenario, $k$ has a more obvious impact on the intensity of consumers' strategic delayed purchasing behavior. From Figure 1(b), we can know that the larger the proportion of service valuation, the lower the intensity of consumers' strategic delayed purchasing behavior under the two scenarios, which means that higher proportion of service valuation can promote more consumers to choose early purchase. In particular, when the proportion of service valuation is relatively low, consumers are more inclined to delay purchase under the centralized scenario; when the proportion of service valuation is relatively high, consumers are more inclined to delay purchase under the decentralized scenario. Next, we analyze the impact of $k$ and $\lambda$ on the corresponding two-period price differences under the two scenarios. Among them, the first period price difference is $p_{G 1}^{D *}-p_{G 1}^{C *}$, and the second period price difference is $p_{G 2}^{D *}-p_{G 2}^{C *}$, as shown in Figure 2 .

It can be seen from Figure 2 (a) that when the service inputefficiency is low (that is, $k$ is larger), the first period price difference is higher under the two scenarios, while the second period price difference is lower. This means that as $k$ increases, the first period PSS price under the decentralized scenario deviates from the optimal price of system, but the second period PSS price under the decentralized scenario gradually approaches the optimal price of system. This shows that $k$ will increase the degree of price distortion in the first period and reduce the degree of price distortion in the second period. From Figure 2(b), we can know that the price differences between the first and second periods of the two scenarios are increasing as the proportion of service valuation $\lambda$ increases, and the price difference in the first period increases faster than the price difference in the second period. This shows that higher proportion of service valuation can increase the degree of price distortion in the first and second periods under the decentralized scenario, and the degree of price distortion in the first period is more obvious. The following analyzes the influence of $k$ and $\lambda$ on the difference of service quality $\left(q^{C *}-\right.$ $\left.q^{D *}\right)$ under the two scenarios, as shown in Figure 3.

From Figure 3(a), it can be seen that the difference between the two service qualities under the two scenarios will show a decreasing trend as $k$ increases, and when the proportion of service valuation $\lambda$ is larger, the difference in service qualities decreases more obviously. This indicates that the improvement of service input-efficiency will lead to a bigger gap between the optimal service quality under the decentralized scenario and centralized scenario. In addition, the proportion of service valuation can increase the impact of $k$ on the difference in service quality. It can be seen from Figure 3(b) that the higher the proportion of service valuation, the bigger the difference in service quality, which means that the proportion of service valuation can widen the gap between optimal service quality under the decentralized scenario and centralized scenario. When the service inputefficiency is higher (that is, $k$ is smaller), the impact of the proportion of service valuation on the difference in service quality is more obvious. The following analyzes the impact of $k$ and $\lambda$ on the loss rate of the system profit $\eta$, as shown in Figure 4 .

From Figure 4(a), it can be seen that the loss rate of system profit $\eta$ under the decentralized scenario will increase with the increase of $k$, and in particular, when the proportion of service valuation is relatively high, the loss rate of the system profit is relatively high. This means that if the service provider improves service input-efficiency will reduce the loss rate of the system profit. From Figure 4(b), it can be seen that when the proportion of service valuation is relatively low (high), the loss rate of the system profit is relatively low 
16

Complexity

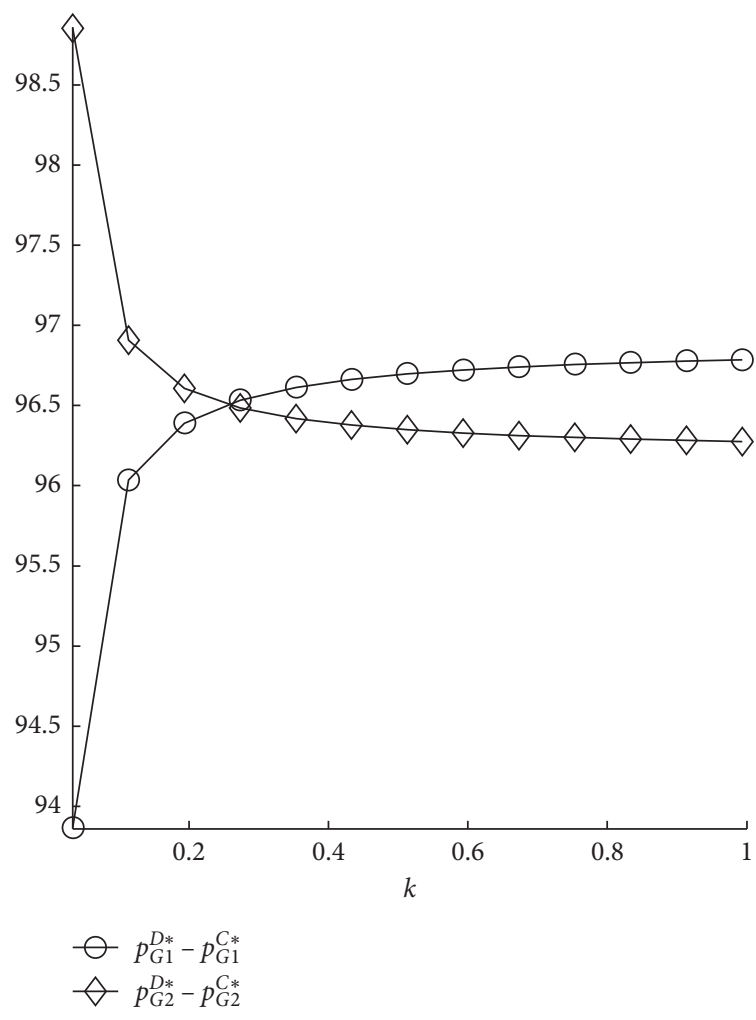

(a)

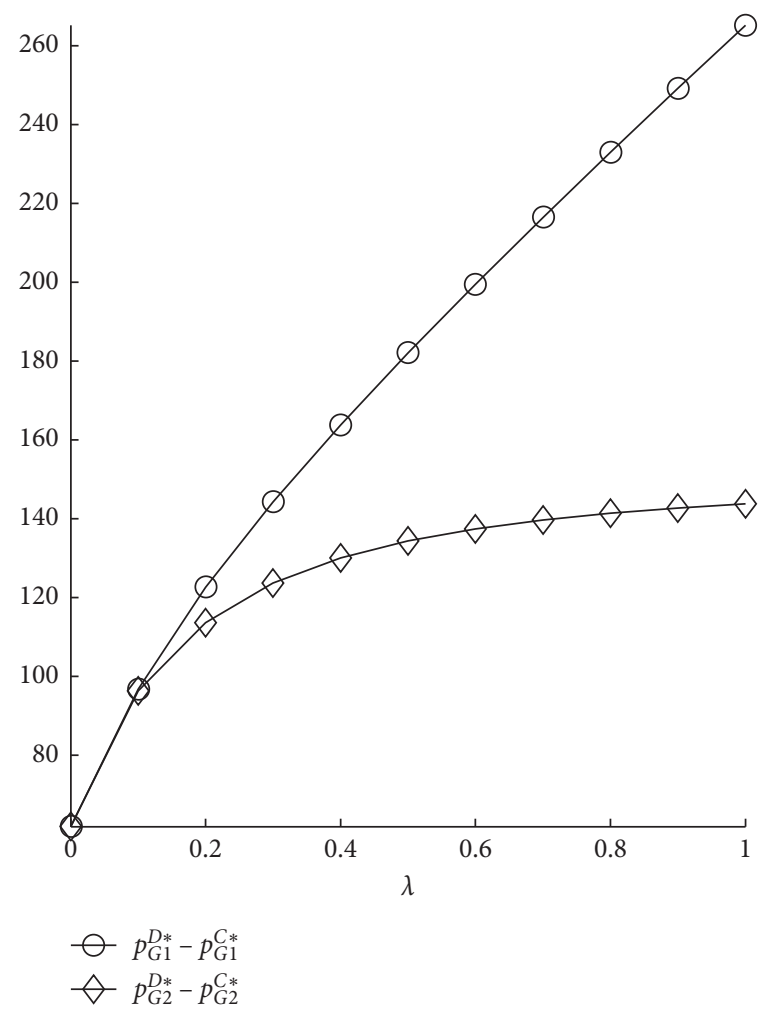

(b)

Figure 2: The impact of $k$ and $\lambda$ on $p_{G i}^{D *}-p_{G i}^{C *}(i=1,2)$.

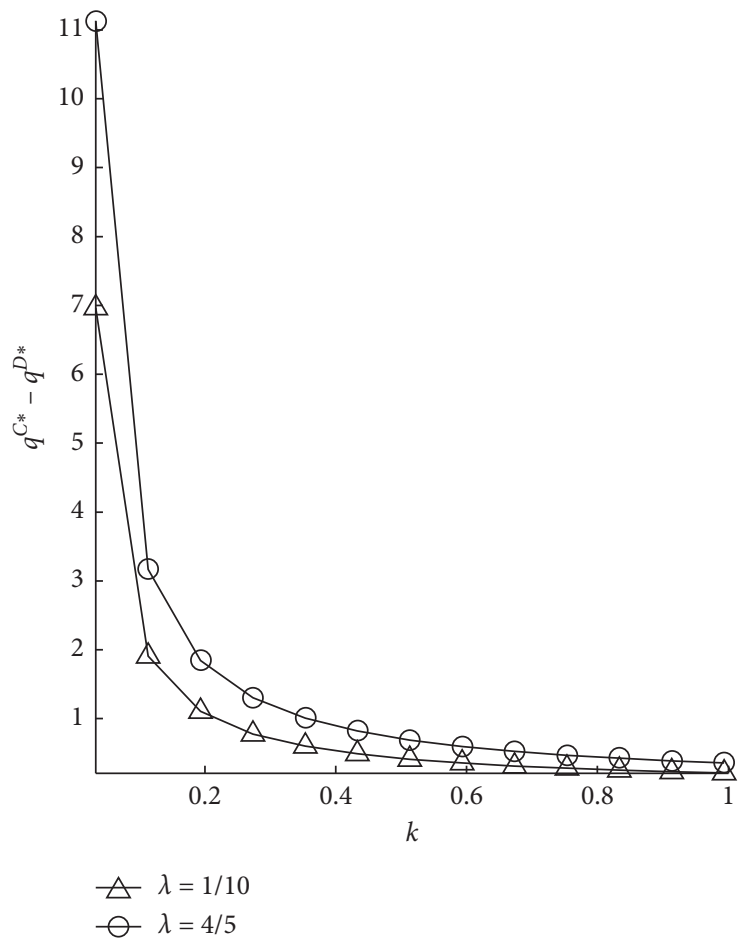

(a)

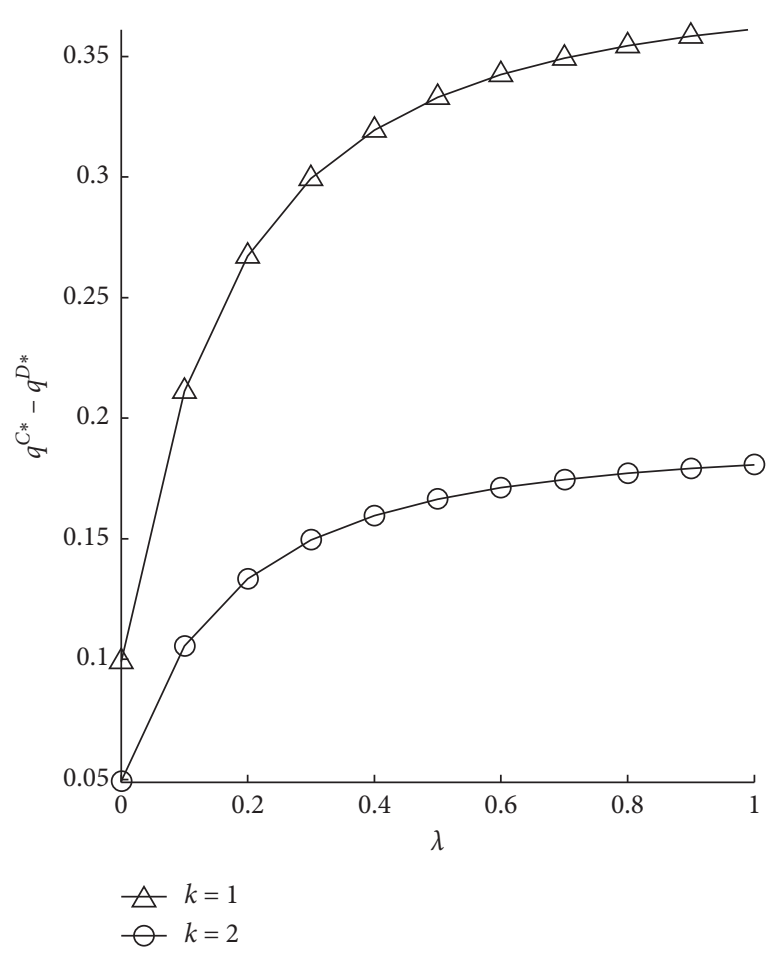

(b)

Figure 3: The impact of $k$ and $\lambda$ on $q^{C *}-q^{D *}$. 


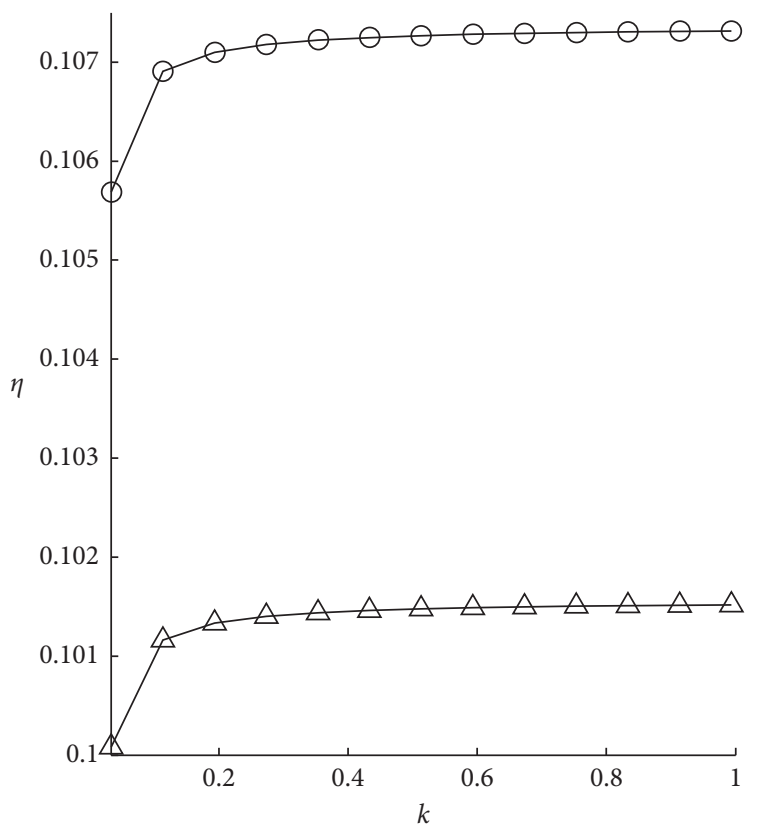

$\triangle \lambda=3 / 4$
$\bigcirc \lambda=4 / 5$

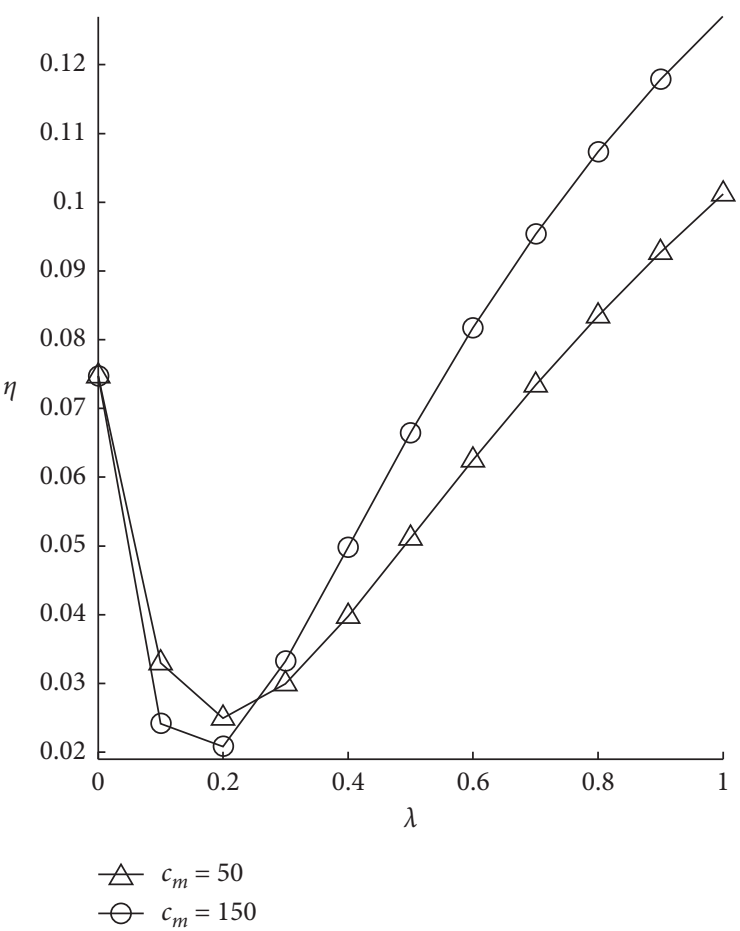

(b)

Figure 4: The impact of $k$ and $\lambda$ on $\eta$.

(high), and in particular, if the manufacturer reduces the unit product cost, the loss rate of system profit will increase (decrease). The following analyzes the impact of the twoperiod revenue sharing ratios $\varphi_{1}$ and $\varphi_{2}$ on the profit difference of the manufacturer and the service provider $\left(\Delta \pi_{M}=\pi_{M}^{\mathrm{RC}}-\pi_{M}^{D *}, \Delta \pi_{S}=\pi_{S}^{\mathrm{RC}}-\pi_{S}^{D *}\right)$ before and after coordination. Let $\lambda=3 / 5$, as shown in Figure 5.

It can be seen from Figure 5(a) that when the second period revenue sharing ratio $\varphi_{2}$ is given, the manufacturer's profit difference and the service provider's profit difference before and after coordination are both linear functions of the first period revenue sharing ratio $\varphi_{1}$. The manufacturer's profit difference before and after coordination decreases monotonically with the increase of $\varphi_{1}$, while the service provider's profit difference before and after coordination increases monotonically with the increase of $\varphi_{1}$. When $\varphi_{1} \geq \varphi_{1}^{a}$, the profit obtained by the manufacturer after coordination is not less than that before coordination, which shows that the manufacturer can achieve Pareto improvement. When $\varphi_{1} \leq \varphi_{1}^{b}$, the profit obtained by the service provider after coordination is not less than that before coordination; that is, the service provider can realize Pareto improvement. In addition, formula (39) given by Proposition 8 can be substituted into the verification; when $\varphi_{1} \in\left[\varphi_{1}^{a}, \varphi_{1}^{b}\right]$, the PSSC can achieve perfect coordination. By calculation, $\varphi_{1}^{a}=0.547$ and $\varphi_{1}^{b}=0.817$. From Figure 5(a), we can see that the revenue sharing ratio $\varphi_{1}$ in the first period has a certain degree of flexibility. Therefore, the distribution of system revenue between the manufacturer and the service provider in the first period will change with the bargaining power of both parties. Similarly, from Figure 5(b), when the first period revenue sharing ratio $\varphi_{1}$ is given and and the second period revenue sharing ratio $\varphi_{2} \in\left[\varphi_{2}^{a}, \varphi_{2}^{b}\right]$, the PSSC can also achieve perfect coordination. By calculation, $\varphi_{2}^{a}=0.178$ and $\varphi_{2}^{b}=0.290$. It can also be seen that the second period revenue sharing ratio $\varphi_{2}$ has a certain degree of flexibility, so the distribution of the second period system revenue between the manufacturer and the service provider will change accordingly with the changes in the bargaining power of both parties. The following analyzes the influence of the proportion of service valuation and service input-efficiency on the transfer payment in the new combined dynamic contract. Let $T_{\text {min }}=\pi_{S}^{D *}-\pi_{S}^{\mathrm{RC}}, \quad T_{\max }=\pi_{M}^{\mathrm{RC}}-\pi_{M}^{D^{*}}, \quad \varphi_{1}=9 / 10, \quad$ and $\varphi_{2}=1 / 1000$, as shown in Figure 6 .

It can be seen from Figure 6(a) that when the two-period revenue sharing ratios $\varphi_{1}$ and $\varphi_{2}$ are given, the transfer payment $T \in\left[T_{\min }, T_{\max }\right]$. As the proportion of service valuation $\lambda$ increases, $T_{\min }$ increases first and then decreases, while $T_{\max }$ gradually decreases, which shows that when $\lambda$ gradually increases, the service provider's two-period profit loss gradually increases and then gradually decreases, while the manufacturer's increased profit gradually decreases after coordination. It can also be found from Figure 6(a) that as $\lambda$ increases, the value range of transfer payment $T$ provided to the service provider gradually decreases, which means that the flexibility of the transfer payment contract gradually decreases. From Figure 6(b), we can see that with the decrease of service input-efficiency (that is, $k$ is large), both $T_{\min }$ and $T_{\max }$ gradually decrease, which shows that when $k$ is large, the two-period profit loss of the service provider gradually decreases, and the manufacturer's increased profit also gradually decreases after coordination. It can also be found from Figure 6(b) that as $k$ increases, the value range of 


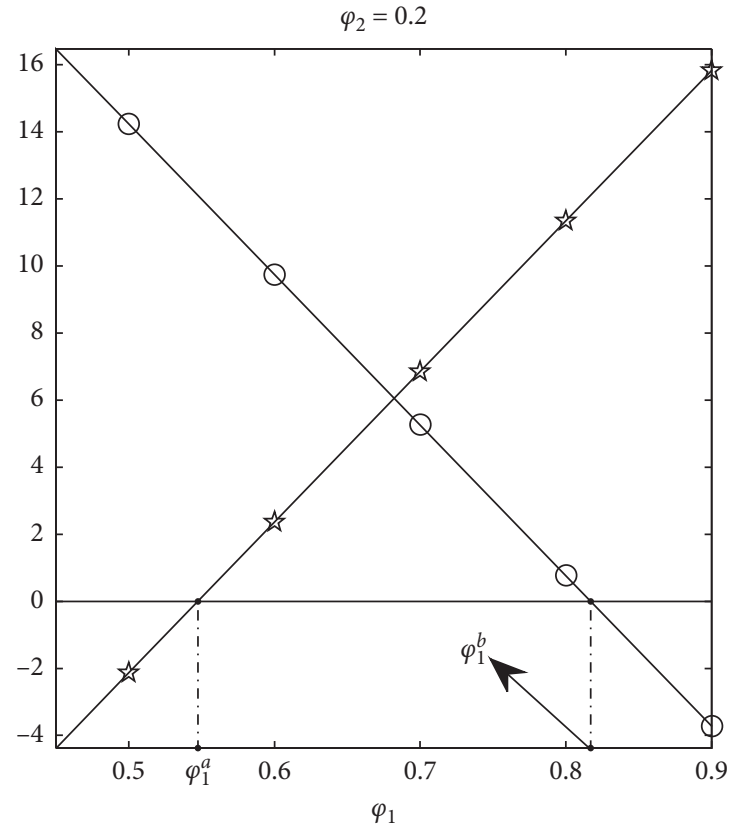

$\curlyvee \Delta \pi_{M}$ 业 $\Delta \pi_{S}$

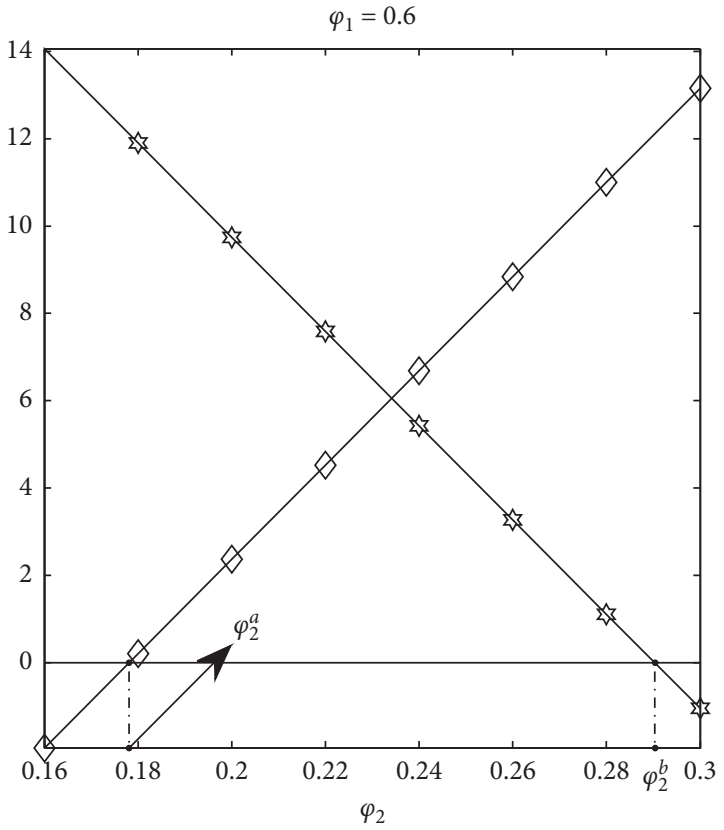

$\Delta \pi_{M}$ $\vartheta \Delta \pi_{S}$

(a)

(b)

Figure 5: The impact of $\varphi_{1}$ and $\varphi_{2}$ on the profit difference $\Delta \pi_{M}$ and $\Delta \pi_{S}$.

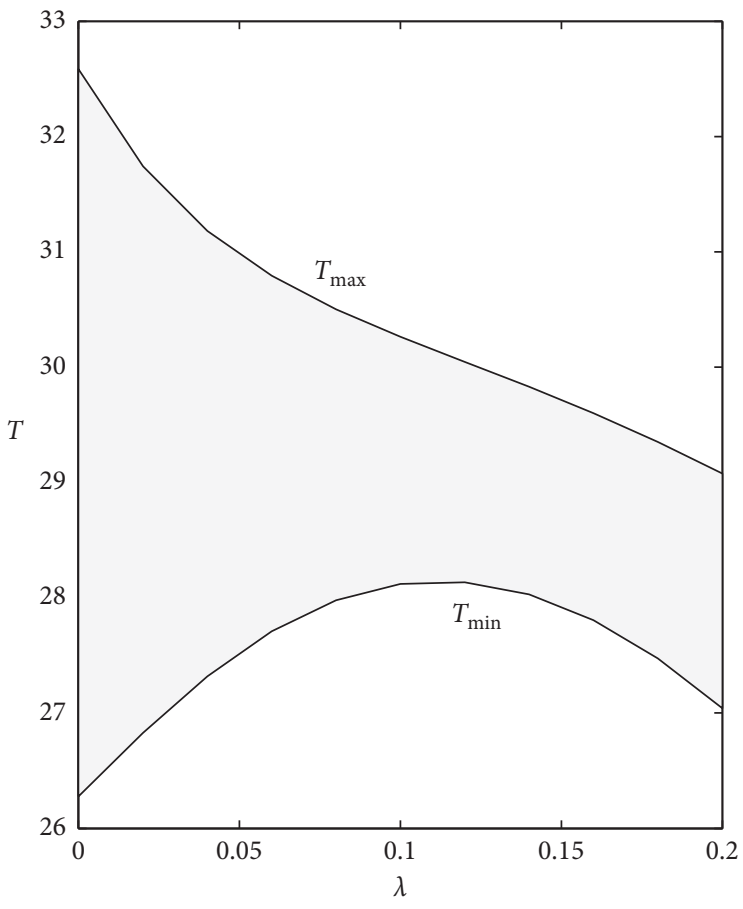

(a)

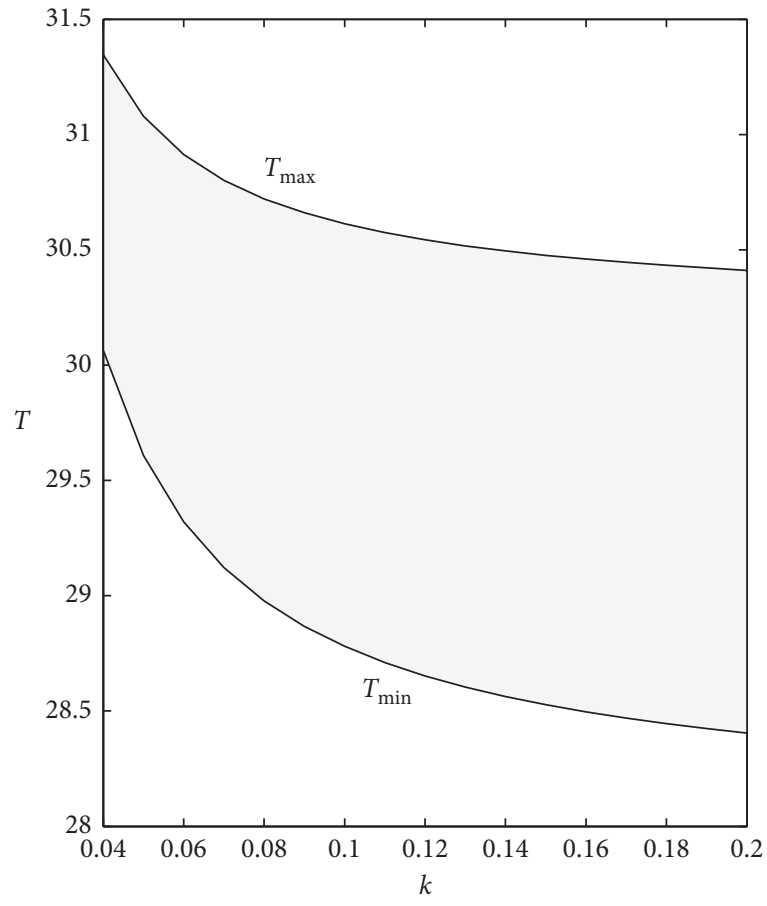

(b)

Figure 6: The impact of $\lambda$ and $k$ on transfer payment. 
the transfer payment $T$ provided to the service provider gradually expands, which means that the flexibility of the transfer payment contract gradually increases.

\section{Conclusion}

As the level of product homogenization is getting more serious and consumers' service requirements are getting higher and higher, firms will increase service investment to improve service quality to obtain market competitive advantage. Meanwhile, firms will bear higher service costs. On the other hand, with the rapid development of the Internet and information technology, consumers get product information or service information is becoming more convenient, which makes consumers getting more and more rational in the purchase process. In the face of consumers' strategic purchasing behavior, how do firms determine service quality and multiperiod sales prices is a problem worth studying. In response to this problem, we build multiperiod dynamic pricing models, which consider consumers' strategic purchasing behavior and service quality. This paper investigates the dynamic decisions of the PSSC in the centralized and decentralized scenarios, compares equilibrium results and supply chain profits under two scenarios, and finds that there are supply chain performance loss and decision bias in the decentralized situation. In order to eliminate the performance loss and decision bias, this paper designs multiperiod combined dynamic contracts that can adjust the decision behavior of supply chain members and ultimately achieves the optimal performance of the PSSC. The main conclusions of this paper are as follows:

(1) The service provider provides the PSS with a higher proportion of service valuation, which will effectively inhibit consumers' strategic purchasing behavior in two scenarios, and this inhibitory effect will be more obvious under the centralized scenario. This means that as the proportion of service valuation increases, the intensity of consumers' strategic delayed purchasing behavior will decrease in two scenarios, and the degree of decline in the centralized scenario is larger. Similarly, the service provider increases service input-efficiency which will inhibit consumers' strategic purchasing behavior, which means that the higher the service input-efficiency, the weaker the intensity of consumers' strategic delayed purchasing behavior. Furthermore, the service provider provides high-value PSS, which will reduce (enhance) the intensity of consumers' strategic delayed purchasing behavior in the decentralized (centralized) scenario.

(2) By comparing equilibrium results of two scenarios, it is found that there are decision bias and performance loss of the PSSC in the decentralized scenario. For example, the service quality is low, the sales prices of two-period PSS are high, and the total profit of PSSC is low. In addition, the increase in the proportion of service valuation will aggravate decision bias in the decentralized scenario. This means that the proportion of service valuation will promote the widening of the service quality gap and increase the price distortion. However, the service provider improves the service input-efficiency which will enhance the promotion effect of the proportion of service valuation to service quality gap in two scenarios and reduce the price distortion of the first period. Nevertheless, in some cases, the improvement of service input-efficiency will enhance the promotion effect of the proportion of service valuation to price distortion in the second period.

(3) In order to eliminate supply chain performance loss, the two-period dynamic contracts are designed to coordinate the decision behavior of the supply chain members. The design of the contracts is closely related to the proportion of service valuation. When the proportion of service valuation is relatively high, the "two-period revenue sharing + service-cost sharing" combined dynamic contract can make the PSSC achieve perfect coordination. However, when the proportion of service valuation is relatively low, the above contract cannot achieve perfect coordination. It is necessary to adopt a "two-period revenue sharing + service-cost sharing + transfer payment" new combined dynamic contract to achieve perfect coordination. Moreover, in the case of supply chain coordination, with the increase of the revenue sharing ratio of the second period, the manufacturer will reduce the wholesale price of the first period and increase the wholesale price of the second period. In addition, the impact of the service input-efficiency (the proportion of service valuation) on service-cost sharing ratio is not monotonous and relates to the revenue sharing ratios of two-period.

The limitation of this paper is that we assume that all consumers are strategic consumers. However, there may be different types of consumers in the market. On the other hand, we assume that both the manufacturer and the service provider know all the information, but the information of both parties may be asymmetric. Therefore, we need to explore the optimal equilibrium results in the case of asymmetric information or multiple types of consumers. Furthermore, we can expand to the situation where firms sell green products to strategic consumers, which will be an interesting study.

\section{Appendix}

Proof. of Proposition 1. First, we solve the price for the second period PSS $p_{\mathrm{G} 2}^{C}$. From formula (11), the optimal solution $p_{G 2}^{C}=\left(V_{0}^{C}+q^{C}+c_{m}\right) / 2$ can be solved; combining formula (9), $V_{0}^{C}=\left(2 p_{G 1}^{C}-3 q^{C}-c_{m}\right) /(1+2 \lambda)$ can be solved. Substituting the above results into formula (9), we can sort out as follows: 


$$
\begin{aligned}
\pi^{C}= & \left(p_{G 1}^{C}-c_{m}\right)\left(1-\frac{2 p_{G 1}^{C}-3 q^{C}-c_{m}}{V_{1}(1+2 \lambda)}\right) \\
& +\frac{\left(p_{G 1}^{C}-q^{C}(1-\lambda)-c_{m}(1+\lambda)\right)^{2}}{V_{1}(1+2 \lambda)^{2}}-\frac{k}{2}\left(q^{C}\right)^{2} .
\end{aligned}
$$

Next, solving the Hessian matrix of $\pi^{C}$ with respect to $\left(p_{G 1}^{C}, q^{C}\right)$ below, we can get $H\left(p_{G 1}^{C}, q^{C}\right)$ :

$$
H\left(p_{G 1}^{C}, q^{C}\right)=\left[\begin{array}{cc}
-\frac{2(1+4 \lambda)}{V_{1}(1+2 \lambda)^{2}} & \frac{1+8 \lambda}{V_{1}(1+2 \lambda)^{2}} \\
\frac{1+8 \lambda}{V_{1}(1+2 \lambda)^{2}} & -\frac{k V_{1}(1+2 \lambda)^{2}-2(1-\lambda)^{2}}{V_{1}(1+2 \lambda)^{2}}
\end{array}\right] .
$$

Owing to

$$
\frac{\partial^{2} \pi^{C}}{\partial p_{G 1}^{2}}=-\frac{2(1+4 \lambda)}{(1+2 \lambda)^{2} V_{1}}<0
$$

$\left|H\left(p_{G 1}^{C}, q^{C}\right)\right|=\left(\left(2 k V_{1}(1+4 \lambda)-4 \lambda-5\right) / V_{1}^{2}(1+2 \lambda)^{2}\right)>0$, which can be seen that $H\left(p_{G 1}^{C}, q^{C}\right)$ is a negative definite matrix; that is, $\pi^{C}$ is the joint concave function of $p_{G 1}^{C}$ and $q^{C}$, solving $\left(\partial \pi^{C} / \partial p_{G 1}^{C}\right)=0$ and $\left(\partial \pi^{C} / \partial q^{C}\right)=0$ simultaneously; then, $p_{G 1}^{C *}$ and $q^{C *}$ can be obtained. Finally, $p_{G 2}^{C *}$ and $V_{0}^{C *}$ are obtained.

Proof of Corollary 1. Easy to get from Proposition 1, omitted.

Proof of Proposition 2. Similar to the proof process of Proposition 1, omitted.

Proof of Corollary 1. Easy to get from Proposition 2, omitted.

Proof of Proposition 3. According to the equilibrium solutions given by Propositions 1 and 2 under the two scenarios, we can get: (1)

$$
\Upsilon^{D *}-\Upsilon^{C *}=\frac{4 \lambda^{2} V_{1}\left(2 k V_{1}-1\right)\left(8 k V_{1}-1\right)^{2}+E_{4} \lambda-E_{5}\left(V_{1}-c_{m}\right)}{2 V_{1} E_{0}\left(2 k V_{1}(1+4 \lambda)-4 \lambda-5\right)}
$$

where $E_{0}=16 k^{2} V_{1}^{2}(8 \lambda+5)-k V_{1}(163+32 \lambda)-2+2 \lambda$,

$$
\begin{aligned}
E_{4}= & 320 k^{3} V_{1}^{4}+48 k^{2} V_{1}^{3}\left(4 k c_{m}-19\right)-18 k V_{1}^{2}\left(20 k c_{m}-31\right) \\
& -V_{1}\left(4 k c_{m}-17\right)-4 c_{m}, \\
E_{5}= & 48 k^{3} V_{1}^{3}-378 k^{2} V_{1}^{2}+495 k V_{1}+13 .
\end{aligned}
$$

Let $\quad E(\lambda)=4 \lambda^{2} V_{1}\left(2 k V_{1}-1\right)\left(8 k V_{1}-1\right)^{2}+E_{4} \lambda-E_{5}$ $\left(V_{1}-c_{m}\right)$.

Next, we need to determine the positive and negative of function $E(\lambda)$. It is easy to know $E_{5}>0$, so we can get $E(\lambda=0)<0$. In addition, because

$$
\begin{aligned}
E(\lambda=1)= & 784 k^{3} V_{1}^{4}+6 k^{2} V_{1}^{3}\left(40 k c_{m}-153\right) \\
& -9 k V_{1}^{2}\left(82 k c_{m}-15\right)+c_{m}\left(491 k V_{1}+9\right)>0,
\end{aligned}
$$

so there is a unique $\lambda_{a}$ (as shown in Proposition 3), when $0<\lambda<\lambda_{a}, \quad E(\lambda)<0$; when $\lambda_{a} \leq \lambda<1, \quad E(\lambda) \geq 0$. Because $\operatorname{sgn}\left(V_{0}^{D *}-V_{0}^{C *}\right)=\operatorname{sgn}(E(\lambda))$, so when $0<\lambda<\lambda_{a}$, $V_{0}^{D *}<V_{0}^{C *}$; when $\lambda_{a} \leq \lambda<1, V_{0}^{D *} \geq V_{0}^{C *}$.

(2) This part conclusion is easy to get, so it is omitted.

Proof of Proposition 4. Since Proposition 4 (1) is easily obtained, it is omitted. The equilibrium solutions under the two scenarios are given by Propositions 1 and 2 and Corollaries 1 and 2, and we can get the following conclusions:

(2) $Q_{1}^{C *}-Q_{1}^{D *}=\left(V_{0}^{D *}-V_{0}^{C *}\right) / V_{1}$, according to Proposition 3 (1), when $0<\lambda<\lambda_{a}, Q_{1}^{D *}>Q_{1}^{C *}$; when $\lambda_{a} \leq \lambda<1, Q_{1}^{D *} \leq Q_{1}^{C *}$.

$$
Q_{2}^{C *}-Q_{2}^{D *}=\frac{4 F_{1} \lambda^{2} V_{1}\left(8 k V_{1}-1\right)+F_{2} \lambda+F_{3}\left(V_{1}-c_{m}\right)}{4 V_{1} E_{0}\left(2 k V_{1}(1+4 \lambda)-4 \lambda-5\right)},
$$


where

$$
\begin{aligned}
F_{1}= & 8 k^{2} V_{1}^{2}-32 k^{2} c_{m} V_{1}+42 k V_{1}-8 k c_{m}+1, \\
F_{2}= & 416 k^{3} V_{1}^{4}-8 k^{2} V_{1}^{3}\left(124 k c_{m}+19\right) \\
& +6 k V_{1}^{2}\left(356 k c_{m}-333\right)+V_{1}\left(372 k c_{m}-55\right)-4 c_{m}, \\
F_{3}= & 184 k^{3} V_{1}^{3}-974 k^{2} V_{1}^{2}+1189 k V_{1}+59 .
\end{aligned}
$$

Let $\quad A(\lambda)=4 F_{1} \lambda^{2} V_{1}\left(8 k V_{1}-1\right)+F_{2} \lambda+F_{3}\left(V_{1}-c_{m}\right)$, and $\operatorname{sgn}\left(Q_{2}^{C *}-Q_{2}^{D *}\right)=\operatorname{sgn}(A(\lambda))$. We can know that the positive and negative of $F_{1}$ are uncertain. When $k \geq(33+\sqrt{2185}) /\left(8 c_{m}\right), F_{1} \geq 0$, and get $A(\lambda)>0$; when $k<(33+\sqrt{2185}) /\left(8 c_{m}\right), F_{1}<0$, and get $A(\lambda)=0$ has a positive root and a negative root, since

$$
\begin{aligned}
A(\lambda=1)= & 856 k^{3} V_{1}^{4}-2 k^{2} V_{1}^{3}\left(1100 k c_{m}-93\right) \\
& +21 k V_{1}^{2}\left(142 k c_{m}-45\right)-c_{m}\left(785 k V_{1}+63\right)>0,
\end{aligned}
$$

so get $A(\lambda)>0$. Therefore, we can get $Q_{2}^{C *}>Q_{2}^{D *}$. $Q_{1}^{C *}$ $+Q_{2}^{C *}-\left(Q_{1}^{D *}+Q_{2}^{D *}\right)=\left(p_{G 2}^{D *}-q^{D *}-\left(p_{G 2}^{C *}-q^{C *}\right)\right) / V_{1}$, according to Proposition 3 (2), we can get

$$
Q_{1}^{C *}+Q_{2}^{C *}>Q_{1}^{D *}+Q_{2}^{D *} .
$$

(3) The profit of the manufacturer and the service provider under the decentralized scenario are added to obtain the profit of the supply chain system. That is, the expressions of total profit in two periods of $\pi_{M}^{D}+\pi_{S}^{D}$ and $\pi^{C}$ are the same, and the optimal profit of the system under the centralized scenario is $\pi^{C *}\left(q^{C *}, p_{G 1}^{C *}, p_{G 2}^{C *}\right)$, because $q^{D *} \neq q^{C *}, \quad p_{G 1}^{D *} \neq p_{G 1}^{C *}$, and $p_{G 2}^{D *} \neq p_{G 2}^{C *}$, so we can get $\pi_{M}^{D *}\left(w_{1}^{D *}, w_{2}^{D *}\right)+\pi_{S}^{D *}\left(q^{D *}, p_{G 1}^{D *}, p_{G 2}^{D *}\right)=\pi^{C *}\left(q^{D *}, \quad p_{G 1}^{D *}\right.$, $\left.p_{G 2}^{D *}\right)<\pi^{C *}\left(q^{C *}, p_{G 1}^{C *}, p_{G 2}^{C *}\right)$.

Proof of Proposition 5. In this section, we only give the proof of Proposition 5 (4). According to the equilibrium solutions given by Propositions 1 and 2, we can get (4)

$$
\frac{\partial^{2}\left(p_{G 2}^{D *}-p_{G 2}^{C *}\right)}{\partial \lambda \partial k}=\frac{V_{1}\left[\begin{array}{c}
H_{1}-128 H_{2} \lambda^{4}\left(8 k V_{1}-1\right)^{2} \\
+H_{3} \lambda^{3}+H_{4} \lambda^{2}+H_{5} \lambda
\end{array}\right]}{4 E_{0}^{3}\left(2 k V_{1}(1+4 \lambda)-4 \lambda-5\right)^{3}}
$$

where

$$
\begin{aligned}
& H_{1}=6885376 k^{7} V_{1}^{8}-256 k^{6} V_{1}^{7}\left(87776 k c_{m}-50343\right) \\
& +2560 k^{5} V_{1}^{6}\left(48046 k c_{m}-103527\right) \\
& -8 k^{4} V_{1}^{5}\left(23284128 k c_{m}-90912755\right) \\
& -4 k^{3} V_{1}^{4}\left(6235172 k c_{m}+181344681\right) \\
& +2 k^{2} V_{1}^{3}\left(105348380 k c_{m}+147699033\right) \\
& -k V_{1}^{2}\left(102668604 k c_{m}+118369519\right) \\
& +V_{1}\left(43205570 k c_{m}+1180866\right)-2127256 c_{m} \text {, } \\
& H_{2}=42752 k^{5} V_{1}^{6}-4 k^{2} V_{1}^{3}\left(42004 k c_{m}+87181\right)-358 c_{m} \\
& +64 k^{4} V_{1}^{5}\left(1072 k c_{m}-6793\right)+2 k V_{1}^{2}\left(55196 k c_{m}+18889\right) \\
& -V_{1}\left(18540 k c_{m}-4809\right)-24 k^{3} V_{1}^{4}\left(1136 k c_{m}-31501\right) \text {, } \\
& H_{3}=706478080 k^{7} V_{1}^{8}-16384 k^{6} V_{1}^{7}\left(30560 k c_{m}+89241\right) \\
& +8192 k^{5} V_{1}^{6}\left(268472 k c_{m}-459807\right) \\
& -512 k^{4} V_{1}^{5}\left(2674464 k c_{m}-18298435\right) \\
& -512 k^{3} V_{1}^{4}\left(4285058 k c_{m}+8550279\right) \\
& +1024 k^{2} V_{1}^{3}\left(1418015 k c_{m}+727548\right) \\
& -128 k V_{1}^{2}\left(2489496 k c_{m}+380317\right) \\
& +V_{1}\left(33936640 k c_{m}-1630560\right)-951488 c_{m}, \\
& H_{4}=925433856 k^{7} V_{1}^{8}-12288 k^{6} V_{1}^{7}\left(31840 k c_{m}+418553\right) \\
& +6144 k^{5} V_{1}^{6}\left(374136 k c_{m}+1522015\right) \\
& -384 k^{4} V_{1}^{5}\left(12688160 k c_{m}+9670709\right) \\
& +52992 k^{3} V_{1}^{4}\left(58523 k c_{m}-77914\right) \\
& +576 k^{2} V_{1}^{3}\left(1972568 k c_{m}+2891393\right) \\
& -384 k V_{1}^{2}\left(1614603 k c_{m}+591526\right) \\
& +V_{1}\left(107816832 k c_{m}-600408\right)-3878448 c_{m}, \\
& H_{5}=265895936 k^{7} V_{1}^{8}+V_{1}\left(114940208 k c_{m}+1665654\right) \\
& +512 k^{5} V_{1}^{6}\left(1936552 k c_{m}+9395367\right) \\
& -32 k^{4} V_{1}^{5}\left(75175392 k c_{m}+180135155\right) \\
& +32 k^{3} V_{1}^{4}\left(90260882 k c_{m}+53534511\right) \\
& -64 k^{2} V_{1}^{3}\left(18066199 k c_{m}-24997884\right) \\
& -8 k V_{1}^{2}\left(72777096 k c_{m}+35312443\right) \\
& -1024 k^{6} V_{1}^{7}\left(161312 k c_{m}+1761963\right)-5029652 c_{m} \text {. }
\end{aligned}
$$


We can judge $H_{2}>0, H_{3}>0, H_{4}>0, H_{5}>0$, and $-128 H_{2} \lambda^{4}\left(8 k V_{1}-1\right)^{2}+H_{3} \lambda^{3}>0$, but we cannot determine the positive and negative of $H_{1}$, and we know $H_{1}$ is a function of increasing $V_{1}$. So, when $k \leq \Delta_{g} / c_{m}$, or $k>\Delta_{g} / c_{m}$ and $V_{1} \geq V_{g}, H_{1} \geq 0$, $\operatorname{so}^{2}\left(p_{G 2}^{D *}-p_{G 2}^{C *}\right) / \partial \lambda \partial k>0$; when $k>\Delta_{g} / c_{m}$ and $V_{1}<V_{g}, H_{1}<0$, where $\Delta_{g}$ and $V_{g}$ are shown in Proposition 5.

Let

$H_{\lambda}=H_{1}-128 H_{2} \lambda^{4}\left(8 k V_{1}-1\right)^{2}+H_{3} \lambda^{3}+H_{4} \lambda^{2}+H_{5} \lambda$.

Consider below when $H_{1}<0$, the positive and negative of the expression $H_{\lambda}$, which can be judged that the expression increases with $\lambda$, and $\left.H_{\lambda}\right|_{\lambda=1}>0$, so there is only one $\lambda_{g}$, when $0<\lambda<\lambda_{g}, \quad H_{\lambda}<0$; when $\lambda_{g} \leq \lambda<1, \quad H_{\lambda} \geq 0$. So, when $k>\Delta_{g} / c_{m}, \quad V_{1}<V_{g}$ and $0<\lambda<\lambda_{g}, \quad \partial^{2}\left(p_{G 2}^{D *}-p_{G 2}^{C *}\right) /$ $\partial \lambda \partial k<0$; when $k>\Delta_{g} / c_{m}, \quad V_{1}<V_{g}$ and $\lambda_{g} \leq \lambda<1$, $\partial^{2}\left(p_{G 2}^{D *}-p_{G 2}^{C *}\right) / \partial \lambda \partial k \geq 0$.

Proof of Proposition 6. First, we solve the second period PSS price $p_{G 2}$ under contract coordination, and the second period profit function of the service provider is $\pi_{S 2}^{\mathrm{RC}}\left(p_{G 2}\right)=\left(\varphi_{2} p_{G 2}-w_{2}\right)\left(V_{0} / V_{1}-\left(p_{G 2}-q\right) / V_{1}\right)$, so we can get $p_{G 2}^{\mathrm{RC} *}=\left(w_{2}+\varphi_{2}\left(q+V_{0}\right)\right) / 2 \varphi_{2}$. In order to achieve supply chain coordination, the price of the second period PSS under contract coordination should be equal to that under the centralized scenario, that is $p_{G 2}^{\mathrm{RC} *}=p_{G 2}^{C *}$, and we can solve $\quad w_{2}=\left(\varphi_{2}\left[\begin{array}{c}2 k V_{1}^{2}(1+2 \lambda)-6 V_{1}(1-\lambda) \\ +c_{m}(1-4 \lambda)\end{array}\right] /\right.$ $\left.\left(2 k V_{1}(1+4 \lambda)-4 \lambda-5\right)\right)-\varphi_{2}\left(q+V_{0}-c_{m}\right)$.
Replace $p_{G 2}^{D *}$ in formula (22) with $p_{G 2}^{C *}$, and then get

$$
V_{0}=\frac{\left(2 c_{m}(1+2 \lambda)-k V_{1}^{2}(1+2 \lambda)+V_{1} \beta_{1}\right)}{\lambda\left(2 k V_{1}(1+4 \lambda)-4 \lambda-5\right)}+\frac{p_{G 1}-q}{\lambda} .
$$
get

Substitute $p_{G 2}^{C *}, w_{2}$, and $V_{0}$ into formula (36), and we can

$$
\begin{aligned}
& \pi_{S}^{\mathrm{RC}}\left(p_{G 1}, q\right) \\
= & \left(\varphi_{1} p_{G 1}-w_{1}\right)\left[\frac{k V_{1}^{2} \beta_{2}+V_{1} \beta_{3}-2 c_{m}(1+2 \lambda)}{\lambda V_{1}\left(2 k V_{1}(1+4 \lambda)-4 \lambda-5\right)}-\beta_{4}\right] \\
+ & \frac{\varphi_{2}\left[\begin{array}{c}
\left(p_{G 1}-(1-\lambda) q\right)\left(2 k V_{1}(1+4 \lambda)-4 \lambda-5\right) \\
-(1+\lambda)\left((1+2 \lambda)\left(k V_{1}^{2}-2 c_{m}\right)-\beta_{1} V_{1}\right)
\end{array}\right]^{2}}{V_{1} \lambda^{2}\left(2 k V_{1}(1+4 \lambda)-4 \lambda-5\right)^{2}}-\beta_{5},
\end{aligned}
$$

where $\beta_{1}=3-3 \lambda-k c_{m}(1+4 \lambda), \quad \beta_{2}=1+4 \lambda+8 \lambda^{2}, \quad \beta_{3}=$ $k c_{m}(1+4 \lambda)-4 \lambda^{2}-2 \lambda-3$, and $\beta_{4}=\left(\left(p_{G 1}-q\right) / \lambda V_{1}\right)$, $\beta_{5}=k q^{2}(1-\xi) / 2$.

In order to ensure that the profit function of the service provider has an optimal solution, that is, to ensure that the above formula is a concave function, it is necessary to satisfy $\varphi_{1}^{2}<2 k V_{1}(1-\xi)\left(\lambda \varphi_{1}-\varphi_{2}\right)+4 \varphi_{1} \varphi_{2}(1-\lambda)$ and $\varphi_{2}<\lambda \varphi_{1}$, and then solve

$$
\begin{aligned}
p_{G 1}^{\mathrm{RC} *}= & \frac{2 L_{1} \varphi_{2} k V_{1}(1+\lambda)(1-\xi)-\varphi_{1}\left(L_{2}+k \lambda V_{1} L_{3}(1-\xi)\right)}{\left(2 k V_{1}(1+4 \lambda)-4 \lambda-5\right)\left(\varphi_{1}\left(\varphi_{1}-4 \varphi_{2}(1-\lambda)\right)-L_{4}\right)} \\
& +\frac{w_{1}\left(\varphi_{1}-2 \varphi_{2}(1-\lambda)-k \lambda V_{1}(1-\xi)\right)}{\varphi_{1}\left(\varphi_{1}-4 \varphi_{2}(1-\lambda)\right)-L_{4}}, \\
q^{\mathrm{RC} *}= & \frac{\varphi_{1} \varphi_{2}\left(4 k V_{1}^{2}\left(1+4 \lambda-2 \lambda^{2}\right)-L_{5}+V_{1} L_{6}\right)-L_{3} \varphi_{1}^{2}}{\left(2 k V_{1}(1+4 \lambda)-4 \lambda-5\right)\left(\varphi_{1}\left(\varphi_{1}-4 \varphi_{2}(1-\lambda)\right)-L_{4}\right)},
\end{aligned}
$$

where

$$
\begin{aligned}
L_{1}= & k V_{1}^{2}(1+2 \lambda)+V_{1}\left(k c_{m}(1+4 \lambda)+3 \lambda-3\right)-2 c_{m}(1+2 \lambda), \\
L_{2}= & 2 \varphi_{2}(1-\lambda)\left[\begin{array}{c}
2 k \lambda V_{1}^{2}(4 \lambda-1)-4 c_{m}(1+2 \lambda) \\
+V_{1}\left(2 k c_{m}(1+4 \lambda)-4 \lambda^{2}+5 \lambda-1\right)
\end{array}\right], \\
L_{3}= & k V_{1}^{2}\left(1+4 \lambda+8 \lambda^{2}\right)-2 c_{m}(1+2 \lambda) \\
& +V_{1}\left(k c_{m}(1+4 \lambda)-4 \lambda^{2}-2 \lambda-3\right), \\
L_{4}= & 2 k V_{1}(1-\xi)\left(\lambda \varphi_{1}-\varphi_{2}\right), \\
L_{5}= & 8 c_{m} \lambda(1+2 \lambda), \\
L_{6}= & 4 k c_{m} \lambda(1+4 \lambda)+10\left(2 \lambda^{2}-\lambda-1\right) .
\end{aligned}
$$

In order to achieve supply chain coordination, the first period PSS price and service quality under contract coordination scenario should be equal to those under the centralized scenario, namely, $p_{G 1}^{\mathrm{RC} *}=p_{G 1}^{\mathrm{C} *}$ and $q^{\mathrm{RC} *}=q^{\mathrm{C} *}$. Furthermore, we can solve the first period product wholesale price $w_{1}^{\mathrm{RC}}$ and service-cost sharing ratio $\xi$ under contract coordination scenario and then solve the second period product wholesale price $w_{2}^{\mathrm{RC}}$ under contract coordination scenario.

Proof of Proposition 7. Since (1) and (2) in Proposition 7 are easily obtained, it is omitted. According to Proposition 6, we can get

(3) $(\partial \xi / \partial \lambda)=-\left(\left(2\left(\varphi_{1}-3 \varphi_{2}\right)\left(V_{1}-c_{m}\right)\left(2 k V_{1}^{2}-9 V_{1}+\right.\right.\right.$ $\left.\left.\left.4 c_{m}\right)\right) / k V_{1}\left(8 V_{1} \lambda-4 \lambda c_{m}+V_{1}-c_{m}\right)^{2}\right)$, and we can know $\operatorname{sgn}(\partial \xi / \partial \lambda)=\operatorname{sgn}\left(\varphi_{1}-3 \varphi_{2}\right)$, since $\varphi_{2}<\lambda \varphi_{1}$, so when $\lambda \leq$ $(1 / 3), \varphi_{1}-3 \varphi_{2}>0$ and $(\partial \xi / \partial \lambda)<0$; when $\lambda>(1 / 3)$ and $\varphi_{2}<(1 / 3) \varphi_{1}, \varphi_{1}-3 \varphi_{2}>0$ and $(\partial \xi / \partial \lambda)<0$; when $\lambda>(1 / 3)$ and $(1 / 3) \varphi_{1} \leq \varphi_{2}<\lambda \varphi_{1}, \varphi_{1}-3 \varphi_{2} \leq 0$ and $(\partial \xi / \partial \lambda) \geq 0$. In 
summary, we can get the conclusion given by Proposition 7 (3).

(4) $(\partial \xi / \partial k)=-\left(\left(2\left(\varphi_{1}-3 \varphi_{2}\right)\left(\lambda V_{1}-V_{1}+c_{m}\right)\right) / k^{2} V_{1}\right.$ $\left.\left(8 \lambda V_{1}-4 \lambda c_{m}+V_{1}-c_{m}\right)\right)$, since $\operatorname{sgn}(\partial \xi / \partial k)=\operatorname{sgn}\left(\left(\varphi_{1}\right.\right.$ $\left.\left.-3 \varphi_{2}\right)\left(\lambda V_{1}-V_{1}+c_{m}\right)\right)$, when $\lambda>1-\left(c_{m} / V_{1}\right), \lambda V_{1}-V_{1}+$ $c_{m}>0$; when $\lambda \leq 1-\left(c_{m} / V_{1}\right), \lambda V_{1}-V_{1}+c_{m} \leq 0$. Because $V_{1}>3 c_{m}+(5 / k)$, we can get $1-\left(c_{m} / V_{1}\right)>(2 / 3)$. Combined with the conclusion of Proposition 7 (3), we can obtain the conclusion of Proposition 7 (4).
Proof. of Proposition 8. In order to encourage supply chain members to participate in the contract to achieve coordination, it is necessary to ensure that all supply chain members achieve Pareto improvement; that is, $\pi_{M}^{\mathrm{RC}}-\pi_{M}^{D} \geq 0$ and $\pi_{S}^{\mathrm{RC}}-\pi_{S}^{D} \geq 0$ are satisfied. First, according to the conditions satisfied by the parameters under the combined contract given in Proposition 6, the total profits of the manufacturer and the service provider in the two-period can be solved as follows:

$$
\begin{aligned}
& \pi_{M}^{\mathrm{RC}}= \frac{\left[\begin{array}{c}
2 \lambda V_{1}\left(2 k \lambda V_{1}^{2}-\lambda V_{1}+2 V_{1}-2 c_{m}\right) \\
+\left(V_{1}-c_{m}\right)^{2}\left(4 k \lambda V_{1}+k V_{1}-2\right)
\end{array}\right]}{2 V_{1}\left(2 k V_{1}(1+4 \lambda)-4 \lambda-5\right)}-\pi_{S}^{\mathrm{RC}}, \\
& \pi_{S}^{\mathrm{RC}}=\left(\begin{array}{c}
\varphi_{1}\left(2 k \lambda V_{1}^{2}-\lambda V_{1}+V_{1}-c_{m}\right) \\
\times\left(8 k \lambda^{2} V_{1}^{2}-V_{1}(1+2 \lambda)^{2}+c_{m}\right)+\varphi_{2} K_{1} K_{2}
\end{array}\right) \\
&\left(V_{1} F^{2}\right)
\end{aligned}
$$

where $F, K_{1}$, and $K_{2}$ are shown in Proposition 8. Since $\pi_{M}^{\mathrm{RC}}-\pi_{M}^{D} \geq 0$, we can solve $\varphi_{2} \leq\left(F \Omega / 4 K_{0} K_{1} K_{2}\right)-\Psi \varphi_{1}$, where $F_{0}, \Omega$, and $\Psi$ are shown in Proposition 8. Since $\pi_{S}^{\mathrm{RC}}-\pi_{S}^{D} \geq 0$, we can get $\varphi_{2} \geq\left(F^{2} \Theta / 16 K_{0}^{2} K_{1} K_{2}\right)-\Psi \varphi_{1}$, where $\Theta$ is shown in Proposition 8. It can be found by calculation that in some cases there will be $\left(F^{2} \Theta / 16 K_{0}^{2} K_{1} K_{2}\right)-\Psi \varphi_{1} \geq \lambda \varphi_{1}$, which leads to formula (39) without solution. Next, solve the case of $\left(F^{2} \Theta / 16 K_{0}^{2} K_{1} K_{2}\right)-\Psi \varphi_{1} \geq \lambda \varphi_{1}$. First judge the positive and negative of $\lambda+\Psi$, since $\lambda+\Psi=J_{0}(\lambda) /\left(K_{1} K_{2}\right)$, where

$$
\begin{aligned}
J_{0}(\lambda)= & \lambda^{3} V_{1}\left[\begin{array}{c}
4 V_{1} k^{2}\left(3 V_{1}-2 c_{m}\right)^{2}-23 V_{1}+12 c_{m} \\
+4 k\left(3 V_{1}^{2}-4\left(V_{1}-c_{m}\right)^{2}\right)
\end{array}\right] \\
& +\lambda^{2}\left(\begin{array}{c}
4 k^{2} V_{1}^{2}\left(V_{1}-c_{m}\right)\left(3 V_{1}-2 c_{m}\right)+27 V_{1}^{2}-35 V_{1} c_{m} \\
-4 k V_{1}\left(9 V_{1}^{2}-11 V_{1} c_{m}+4 c_{m}^{2}\right)+12 c_{m}^{2}
\end{array}\right) \\
& +\lambda V_{1}\left(V_{1}-c_{m}\right)\left(k\left(V_{1}-c_{m}\right)\left(k V_{1}-3\right)-2 k V_{1}-3\right)-\left(V_{1}-c_{m}\right)^{2}
\end{aligned}
$$

Just judge the positive or negative of $J_{0}(\lambda)$, and we can judge $\left(\partial J_{0}(\lambda) / \partial \lambda\right)>0, J_{0}(\lambda=0)<0, J_{0}(\lambda=1)>0$, so there is only one $\lambda_{k}$, when $0<\lambda \leq \lambda_{k}, J_{0}(\lambda) \leq 0$; when $\lambda_{k}<\lambda<1$, $J_{0}(\lambda)>0$. Therefore, when $0<\lambda \leq \lambda_{k}$, or $\lambda_{k}<\lambda<1$ and $\varphi_{1} \leq\left(F^{2} \Theta / 16 K_{0}^{2} K_{1} K_{2}(\lambda+\Psi)\right), \quad\left(F^{2} \Theta / 16 K_{0}^{2} K_{1} K_{2}\right)-\Psi \varphi_{1} \geq$ $\lambda \varphi_{1}$; when $\lambda_{k}<\lambda<1$ and $\left(F^{2} \Theta / 16 K_{0}^{2} K_{1} K_{2}(\lambda+\Psi)\right)<\varphi_{1}<1$, $\left(F^{2} \Theta / 16 K_{0}^{2} K_{1} K_{2}\right)-\Psi \varphi_{1}<\lambda \varphi_{1}$, where $\quad \lambda_{k}=\{0<\lambda<1 \mid$ $\left.J_{0}(\lambda)=0\right\}$. Through calculations, it may exist $\left(F^{2} \Theta /\right.$ $\left.16 K_{0}^{2} K_{1} K_{2}(\lambda+\Psi)\right) \geq 1$, that is, $F^{2} \Theta-16 K_{0}^{2} K_{1} K_{2}$ $(\lambda+\Psi) \geq 0$. In addition, $\partial\left(F^{2} \Theta-16 K_{0}^{2} K_{1} K_{2}(\lambda+\Psi)\right) / \partial \lambda$ is not monotonous to increase first and then decrease,
$\partial\left(F^{2} \Theta-16 K_{0}^{2} K_{1} K_{2}(\lambda+\Psi)\right) / \partial \lambda$ is first positive and then negative, and $\left.\left(F^{2} \Theta-16 K_{0}^{2} K_{1} K_{2}(\lambda+\Psi)\right)\right|_{\lambda=\lambda_{k}}>0, \quad\left(F^{2} \Theta-\right.$ $\left.16 K_{0}^{2} K_{1} K_{2}(\lambda+\Psi)\right)\left.\right|_{\lambda=1}<0$, so there is only one $\lambda_{r}$ $\left(\lambda_{k}<\lambda_{r}<1\right)$, when $\lambda_{k}<\lambda \leq \lambda_{r},\left(F^{2} \Theta / 16 K_{0}^{2} K_{1} K_{2}(\lambda+\Psi)\right) \geq 1$; when $\lambda_{r}<\lambda<1,\left(F^{2} \Theta / 16 K_{0}^{2} K_{1} K_{2}(\lambda+\Psi)\right)<1$, where

$$
\lambda_{r}=\left\{\lambda_{k}<\lambda<1 \mid F^{2} \Theta-16 K_{0}^{2} K_{1} K_{2}(\lambda+\Psi)=0\right\} .
$$

In summary, when $0<\lambda \leq \lambda_{r}$, we can get $\left(F^{2} \Theta / 16 K_{0}^{2} K_{1} K_{2}\right)-\Psi \varphi_{1} \geq \lambda \varphi_{1}$, which leads to equation (39) without solution; that is, the contract cannot achieve perfect 
coordination; when $\lambda_{r}<\lambda<1$, the contract can achieve perfect coordination.

Proof of Proposition 9. Easy to get from Proposition 6, omitted.

\section{Data Availability}

The data used to support the findings of this study are included within the article.

\section{Conflicts of Interest}

The authors declare that they have no conflicts of interest.

\section{Acknowledgments}

This work was supported by the National Natural Science Foundation of China (grant nos. 72061004, 71661003, and 71661004), the Science and Technology Foundation of Guizhou Provincial (grant nos. [2020]1Y286 and ZK[2021]323), and the Research Funds of Guizhou University of Finance and Economics (grant nos. 2020XYB05 and 2018YJ35).

\section{References}

[1] mt.ironge.com, "JD 618 sales exceeded 200 billion! Increased by $26.57 \%$ over last year," 2019, https://mt.ironge.com.cn/ finance/money/17391.html.

[2] chyxx.com, "Analysis of sales, transaction volume, logistics order volume and sales of major e-commerce platforms in 2019 on double 11," 2019, https://www.chyxx.com/industry/ 201911/805087.html.

[3] H. Nair, "Intertemporal price discrimination with forwardlooking consumers: application to the US market for console video-games," Quantitative Marketing and Economics, vol. 5, no. 3, pp. 239-292, 2007.

[4] Y. Aviv and A. Pazgal, "Optimal pricing of seasonal products in the presence of forward-looking consumers," Manufacturing \& Service Operations Management, vol. 10, no. 3, pp. 339-359, 2008.

[5] Tencent.com, "Cook went all out, iPhone 11 Pro Max fell to the new low price, netizens: buy early," 2019, https://new.qq. com/omn/20191020/20191020A04TIL00.\%20html.

[6] Tencent.com, "The price of iPhone 11 Pro Max is reduced by 2500 yuan, and the starting price has dropped to 7099 yuan!," 2020, https://new.qq.com/rain/a/20200806A06C\%202000.

[7] D. Besanko and W. L. Winston, "Optimal price skimming by a monopolist facing rational consumers," Management Science, vol. 36, no. 5, pp. 555-567, 1990.

[8] Q. Liu and D. Zhang, "Dynamic pricing competition with strategic customers under vertical product differentiation," Management Science, vol. 59, no. 1, pp. 84-101, 2013.

[9] C. Liang, M. Çakanyıldırım, and S. P. Sethi, "Analysis of product rollover strategies in the presence of strategic customers," Management Science, vol. 60, no. 4, pp. 1033-1056, 2014.

[10] C. Liang, M. Çakanyildirim, and S. P. Sethi, "Can strategic customer behavior speed up product innovation?" Production and Operations Management, vol. 27, no. 8, pp. 1516-1533, 2018.
[11] Z. Guo and J. Chen, "Multigeneration product diffusion in the presence of strategic consumers," Information Systems Research, vol. 29, no. 1, pp. 206-224, 2018.

[12] J. Liu, X. Zhai, and L. Chen, "Optimal pricing strategy under trade-in program in the presence of strategic consumers," Omega, vol. 84, pp. 1-17, 2019.

[13] G. P. Cachon and R. Swinney, "Purchasing, pricing, and quick response in the presence of strategic consumers," Management Science, vol. 55, no. 3, pp. 497-511, 2009.

[14] G. P. Cachon and R. Swinney, "The value of fast fashion: quick response, enhanced design, and strategic consumer behavior," Management Science, vol. 57, no. 4, pp. 778-795, 2011.

[15] Y. Wang, J. Zhang, T. C. E. Cheng, and G. Hua, "Quick response under strategic consumers with risk preference and decreasing valuation," International Journal of Production Research, vol. 56, no. 1-2, pp. 72-85, 2018.

[16] J. Dong and D. D. Wu, "Two-period pricing and quick response with strategic customers," International Journal of Production Economics, vol. 215, pp. 165-173, 2019.

[17] M. Yu, L. Debo, and R. Kapuscinski, "Strategic waiting for consumer-generated quality information: dynamic pricing of new experience goods," Management Science, vol. 62, no. 2, pp. $410-435,2016$.

[18] P. Du and Q. Chen, "Skimming or penetration: optimal pricing of new fashion products in the presence of strategic consumers," Annals of Operations Research, vol. 257, no. 1-2, pp. 275-295, 2017.

[19] Y. Aviv, M. M. Wei, and F. Zhang, "Responsive pricing of fashion products: the effects of demand learning and strategic consumer behavior," Management Science, vol. 65, no. 7, pp. 2982-3000, 2019.

[20] J. Zhao, J. Qiu, Y. W. Zhou, X. J. Hu, and A. F. Yang, "Quality disclosure in the presence of strategic consumers," Journal of Retailing and Consumer Services, vol. 55, Article ID 102084, 2020.

[21] G. N. Liu, Z. Z. Guan, and H. Wang, "Dynamic pricing under cost reduction in the presence of myopic and strategic consumers," Discrete Dynamics in Nature and Society, vol. 2019, Article ID 3272875, 15 pages, 2019.

[22] K. Chen, Y. Zha, L. C. Alwan, and L. Zhang, "Dynamic pricing in the presence of reference price effect and consumer strategic behaviour," International Journal of Production Research, vol. 58, no. 2, pp. 546-561, 2019.

[23] N. Zhao, Q. Wang, P. Cao, and J. Wu, "Dynamic pricing with reference price effect and price-matching policy in the presence of strategic consumers," Journal of the Operational Research Society, vol. 70, no. 12, pp. 2069-2083, 2019.

[24] C. Li, M. Chu, C. Zhou, and L. Zhao, "Two-period discount pricing strategies for an e-commerce platform with strategic consumers," Computers \& Industrial Engineering, vol. 147, Article ID 106640, 2020.

[25] C. Che, Z. H. Zhang, X. G. Zhang, and Y. Chen, "Two-stage pricing decision for low-carbon products based on consumer strategic behaviour," Complexity, vol. 2021, Article ID 6633893, 12 pages, 2021.

[26] X. Su and F. Zhang, "Strategic customer behavior, commitment, and supply chain performance," Management Science, vol. 54, no. 10, pp. 1759-1773, 2008.

[27] D. Yang, E. Qi, and Y. Li, "Quick response and supply chain structure with strategic consumers," Omega, vol. 52, pp. 1-14, 2015.

[28] R. Ahmadi, F. Iravani, and H. Mamani, "Supply chain coordination in the presence of gray markets and strategic 
consumers," Production and Operations Management, vol. 26, no. 2, pp. 252-272, 2017.

[29] Y.-T. Lin, A. K. Parlaktürk, and J. M. Swaminathan, "Are strategic customers bad for a supply chain?” Manufacturing \& Service Operations Management, vol. 20, no. 3, pp. 481-497, 2018.

[30] M. O. Kabul and A. K. Parlaktürk, "The value of commitments when selling to strategic consumers: a supply chain perspective," Management Science, vol. 65, no. 10, pp. 4754-4770, 2019.

[31] T. S. Baines, H. W. Lightfoot, S. Evans et al., "State-of-the-art in product-service systems," Proceedings of the Institution of Mechanical Engineers, Part B: Journal of Engineering Manufacture, vol. 221, no. 10, pp. 1543-1552, 2007.

[32] N. Morelli, "Developing new product service systems (PSS): methodologies and operational tools," Journal of Cleaner Production, vol. 14, no. 17, pp. 1495-1501, 2006.

[33] M. Qu, S. Yu, D. Chen, J. Chu, and B. Tian, "State-of-the-art of design, evaluation, and operation methodologies in product service systems," Computers in Industry, vol. 77, pp. 1-14, 2016.

[34] F. Mahut, J. Daaboul, M. Bricogne, and B. Eynard, "Productservice systems for servitization of the automotive industry: a literature review," International Journal of Production Research, vol. 55, no. 7, pp. 2102-2120, 2017.

[35] J. Jiang, Y. Li, L. D. Li, C. C. Zhou, Y. X. Huo, and Q. Li, “An innovation design approach for product service systems based on TRIZ and function incentive," Complexity, vol. 2021, Article ID 5592272, 11 pages, 2021.

[36] F. Zhang, L. C. Jia, and W. Z. Han, "Research on designing an industrial product-service system with uncertain customer demands," Complexity, vol. 2021, Article ID 8897539, 20 pages, 2021.

[37] J. C. Ferrer, H. Mora, and F. Olivares, "On pricing of multiple bundles of products and services," European Journal of Operational Research, vol. 206, no. 1, pp. 197-208, 2010.

[38] M. S. Pang and H. Etzion, "Research note-analyzing pricing strategies for online services with network effects," Information Systems Research, vol. 23, no. 4, pp. 1364-1377, 2012.

[39] B. Yang and C. T. Ng, "Pricing problem in wireless telecommunication product and service bundling," European Journal of Operational Research, vol. 207, no. 1, pp. 473-480, 2010.

[40] X. Zhang, X. Han, X. Liu, R. Liu, and J. Leng, "The pricing of product and value-added service under information asymmetry: a product life cycle perspective," International Journal of Production Research, vol. 53, no. 1, pp. 25-40, 2015.

[41] B. Dan, S. Zhang, and M. Zhou, "Strategies for warranty service in a dual-channel supply chain with value-added service competition," International Journal of Production Research, vol. 56, no. 17, pp. 5677-5699, 2018.

[42] W. Xie, Z. Jiang, Y. Zhao, and X. Shao, "Contract design for cooperative product service system with information asymmetry," International Journal of Production Research, vol. 52, no. 6, pp. 1658-1680, 2014.

[43] D. Yang and T. Xiao, "Coordination of a supply chain with loss-averse consumers in service quality," International Journal of Production Research, vol. 55, no. 12, pp. 3411-3430, 2017.

[44] M. Chen, Q. Hu, and H. Wei, "Interaction of after-sales service provider and contract type in a supply chain," International Journal of Production Economics, vol. 193, pp. 514-527, 2017.
[45] R. Pascual, M. Siña, G. Santelices, M. Román, and E. López Droguett, "Optimal channel coordination in use-based product-service system contracts," International Journal of Production Research, vol. 55, no. 23, pp. 1-11, 2017.

[46] K. Wang, S. Chen, Z. Jiang, W. Zhou, and N. Geng, "Capacity allocation of an integrated production and service system," Production and Operations Management, vol. 30, 2021.

[47] Z. T. Xu, A. Elomri, Q. Zhang, C. J. Liu, and L. Shi, "Status review and research strategies on product-service supply chain," Proceedings of the Institution of Mechanical Engineers Part B-Journal of Engineering Manufacture, vol. 234, no. 8, pp. 1075-1086, 2020.

[48] A. Taleizadeh, M. Noori-Daryan, and S. S. Sana, "Manufacturing and selling tactics for a green supply chain under a green cost sharing and a refund agreement," Journal of Modelling in Management, vol. 15, no. 4, pp. 1419-1450, 2020.

[49] H. Y. Fu, J. W. Li, Y. J. Li, S. Z. Huang, and X. K. Sun, "Risk transfer mechanism for agricultural products supply chain based on weather index insurance," Complexity, vol. 2018, Article ID 2369423, 17 pages, 2018. 